\title{
Flow climatology for physicochemical properties of dichotomous aerosol over the western North Atlantic Ocean at Bermuda
}

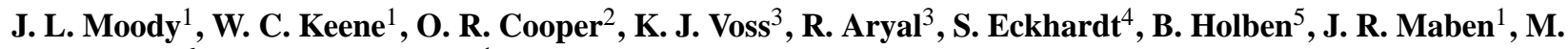 \\ A. Izaguirre ${ }^{6}$, and J. N. Galloway ${ }^{1}$ \\ ${ }^{1}$ Department of Environmental Sciences, University of Virginia, Charlottesville, VA, USA \\ ${ }^{2}$ Cooperative Institute for Research in Environmental Sciences (CIRES), University of Colorado, and NOAA Earth System \\ Research Laboratory, Boulder, CO, USA \\ ${ }^{3}$ Physics Department, University of Miami, Miami, FL, USA \\ ${ }^{4}$ Norwegian Institute for Air Research, Kjeller, Norway \\ ${ }^{5}$ Goddard Space Flight Center, NASA, Greenbelt, MD, USA \\ ${ }^{6}$ Division of Marine and Atmospheric Chemistry, University of Miami, Miami, FL, USA
}

Correspondence to: J. L. Moody (moody@virginia.edu)

Received: 20 July 2013 - Published in Atmos. Chem. Phys. Discuss.: 29 August 2013

Revised: 26 November 2013 - Accepted: 3 December 2013 - Published: 22 January 2014

\begin{abstract}
Dichotomous aerosols (nominal super- and sub$\mu \mathrm{m}$-diameter size fractions) in sectored on-shore flow were sampled daily from July 2006 through June 2009, at the Tudor Hill Atmospheric Observatory (THAO) on the western coast of Bermuda $\left(32.27^{\circ} \mathrm{N}, 64.87^{\circ} \mathrm{W}\right)$ and analyzed for major chemical and physical properties. FLEXPART retroplumes were calculated for each sampling period and aerosol properties were stratified accordingly based on transport from different regions. Transport from the northeastern United States (NEUS) was associated with significantly higher (factors of 2 to 3 based on median values) concentrations of bulk particulate non-sea-salt (nss) $\mathrm{SO}_{4}^{2-}, \mathrm{NO}_{3}^{-}$, and $\mathrm{NH}_{4}^{+}$and associated scattering and absorption at $530 \mathrm{~nm}$, relative to transport from Africa (AFR) and the oceanic background. These differences were driven primarily by higher values associated with the sub- $\mu \mathrm{m}$ size fraction under NEUS flow. We estimate that $75( \pm 3) \%$ of the NEUS nss $\mathrm{SO}_{4}^{2-}$ was anthropogenic in origin, while only $25( \pm 9) \%$ of the AFR nss $\mathrm{SO}_{4}^{2-}$ was anthropogenic. Integrating over all transport patterns, the contribution of anthropogenic sulfate has dropped $14.6 \%$ from the early 1990s. Bulk scattering was highly correlated with bulk nss $\mathrm{SO}_{4}^{2-}$ in all flow regimes but the corresponding regression slopes varied significantly reflecting differential contributions to total scattering by associated aerosol components. Absorption by super- $\mu$ m aerosol in transport from the NEUS versus AFR was similar although
\end{abstract}

the super- $\mu \mathrm{m}$ aerosol size fraction accounted for a relatively greater contribution to total absorption in AFR flow. Significantly greater absorption Ångström exponents (AAEs) for AFR flow reflects the wavelength dependence of absorption by mineral aerosols; lower AAEs for NEUS flow is consistent with the dominance of absorption by combustionderived aerosols. Higher AOD associated with transport from both the NEUS and AFR relative to oceanic background flow results in a top of atmosphere direct radiative forcing on the order of -1.6 to $-2.5 \mathrm{~W} \mathrm{~m}^{-2}$, respectively, showing these aerosols drive cooling. The dominance of transport from the NEUS on an annual basis coupled with the corresponding decreases in anthropogenic nss $\mathrm{SO}_{4}^{2-}$ aerosols since the early 1990s implies that emission reductions in the US account for a decline in atmospheric cooling over the western North Atlantic Ocean during this period.

\section{Introduction}

Tropospheric aerosols influence earth's climate system directly by scattering and absorbing incoming and outgoing radiation and indirectly by modulating the microphysical properties of clouds (e.g., Albrecht, 1989; Charlson and Heizenberg, 1995; Ramanathan et al., 2001; Kaufman et al., 2002; Andreae, 2009; Clarke and Kapustin, 2010). Scattering and 
absorption reduce radiative transfer through the atmosphere resulting in net cooling at the surface but absorption also warms the atmosphere thereby influencing its thermodynamic properties and, in heavily impacted regions, suppressing cloud formation (e.g., Koren et al., 2004). In addition, based on their size and hygroscopicity, aerosols serve as cloud condensation nuclei $(\mathrm{CCN})$. For a given set of conditions, the number concentration of $\mathrm{CCN}$ regulates the corresponding number concentration and size distribution of cloud droplets and thus cloud brightness and evolution, surface irradiance, precipitation efficiency, the hydrologic cycle, and associated feedbacks (e.g., Andreae et al., 2004). Outstanding uncertainties regarding the overall impacts of aerosols on radiative transfer are among the major factors currently limiting our understanding of and ability to predict global climate change (IPCC, 2007).

Large, intensive field campaigns and associated modeling have contributed much towards resolving details of aerosol sources, characteristics, processing, optical properties, and influences on radiative transfer (e.g., Bates et al., 2006). A primary underlying motivation for many such campaigns is to quantify the climatic influences of aerosols from major anthropogenic and natural sources. Consequently, intensives have often targeted conditions within or downwind of major source regions for aerosols and precursors and, due in part to cost, most are of relatively short duration (4 to 8 weeks). Examples include investigations of pollutant plumes from a number of different global regions (transported) over downwind location(s) including (1) from North America over the western North Atlantic Ocean (NAO), the Tropospheric Aerosol Radiative Forcing Observational Experiment (TARFOX, Russell et al., 1999), the New England Air Quality Study (NEAQS, Quinn and Bates, 2005), and the International Consortium in Transport and Transformation campaign (ICARTT, Sierau et al., 2006), (2) from Europe over the southeastern North Atlantic, the Aerosol Characterization Experiment 2 (ACE-2; Quinn and Bates, 2005), (3) from the Indian subcontinent over the Indian Ocean, the Indian Ocean Experiment (INDOEX, Quinn and Bates, 2005), (4) from eastern Asia transported over the western North Pacific (ACE-Asia, Quinn and Bates, 2005), and (5) from Mexico City over the Gulf of Mexico, the Megacity Initiative: Local and Global Research Observations (MILAGRO, Molina et al., 2010), among others.

Despite the rich detail that emerges from comprehensive, short-term campaigns, such studies are not sufficient to produce the reliable aerosol climatologies needed for model development and testing (Heintzenberg et al., 2003). Intensives are typically conducted over relatively narrow ranges in time and space. Because the chemical and optical properties of plumes continue to evolve following advection downwind of study regions, such campaigns may not capture the full impact of aerosols from a given source type or region on radiative transfer nor can they directly evaluate the representativeness of results in the context of interannual variability.
In addition, most investigations have been conducted during warmer months when faster photochemistry and higher temperatures sustain higher oxidant levels and faster rates of chemical transformation and secondary aerosol production. During warmer months, ammonia emitted from agricultural activities and reaction products of non-methane hydrocarbons emitted by terrestrial biota contribute significantly to the nucleation and growth of new particles whereas during colder months these sources are greatly reduced or essentially shut down. During cooler months, direct emissions of aerosols from deflation of surface soils and of aerosols and precursors from biomass burning are also generally lower, the temperature-dependent phase partitioning of semivolatile species is shifted towards the particulate phase, and some countries (including the US) suspend regulatory controls on major aerosol precursors such as $\mathrm{NO}_{\mathrm{x}}$ emitted from power plants. Finally, wind fields (and the associated production of marine aerosol from the surface ocean), cloud cover, and precipitation, all which modulate aerosol evolution, vary seasonally over most of the globe. Consequently, the physicochemical characteristics of pollutant plumes, the nature and rates at which they evolve chemically and optically, and their areal extents vary seasonally, which poses challenges for extrapolating results from short-term intensive campaigns over space and time. Remotely sensed aerosol properties from ground networks such as the Aerosol Robotic Network (AERONET) (e.g., Holben et al., 2001) and the micro pulse lidar network (MPLNET) (Welton et al., 1999), and from the growing constellation of earth-observing satellites provide useful context in this regard. However, the in situ observations necessary to constrain relationships between aerosol chemical composition, radiative effects, and climatic consequences over multi-year periods are quite limited.

Longer term records of aerosol properties that compliment results from intensive campaigns have been generated at several observatories globally including sites in the North and South Pacific as part of the Sea-Air Exchange Experiment (SEAREX) (Prospero and Savoie, 1989) and in the NAO region as part of the Atmosphere-Ocean Chemistry Experiment (AEROCE) (Arimoto et al., 1995; Savoie et al., 2002) among others. These data records are used widely by the community to parameterize and test global chemical transport and climate models. Cost and logistical considerations dictate that such long-term programs target subsets of key analytes that can be quantified reliably using measurement techniques that are both robust and require minimal servicing in the field. Similarly, temporal resolution in measurements may be sacrificed to accommodate generation of longer term records.

The study through which results reported herein were generated was a three-year effort designed to augment and extend the data records for aerosol and precipitation characteristics at Bermuda, which are among the longest-duration high-quality time series that have been generated to date (Galloway et al., 1982, 1989, 1993; Arimoto et al., 1995; 
Savoie et al., 2002). Bermuda is also significantly influenced over the year by air masses containing aged emission products from North America, North Africa, and Europe as well as aged, relatively clean marine air from the central North Atlantic Ocean. The primary objectives of the study were (1) to extend the existing time series of aerosol and precipitation characteristics at Bermuda and evaluate long-term trends, (2) to augment the resolution of the analytical suite by characterizing dichotomous rather than bulk aerosol and by measuring additional aerosol properties including sizeresolved spectral absorption and elemental and organic carbon (EC/OC), and (3) to develop a climatology of aerosol and precipitation properties as functions of season and transport regime and the associated source regions. This paper reports the flow climatology for aerosol chemical and optical properties based on the three-year period of observation and evaluates the associated environmental implications.

\section{Methods}

\subsection{Sampling site, periods, and protocols}

From July 2006 to June 2009, the chemical and physical properties of ambient aerosols were characterized at the Tudor Hill Atmospheric Observatory (THAO) on the western coast of Bermuda $\left(32.27^{\circ} \mathrm{N}, 64.87^{\circ} \mathrm{W}\right)$. The observatory includes a $23 \mathrm{~m}$-tall scaffolding tower and two laboratory containers configured with clean benches, deionized water, and associated electronics positioned on a steep slope approximately $25 \mathrm{~m}$ above mean sea level. To minimize local influences, time-integrated sampling was controlled by sensors that activated pumps only during periods of no precipitation when surface winds were off the ocean sector at speeds greater than $1 \mathrm{~m} \mathrm{~s}^{-1}$. Meteorological conditions were recorded continuously from the top of the tower.

Dichotomous aerosols (nominal super- and sub- $\mu \mathrm{m}-$ diameter size fractions) were sampled in parallel at a rate of $0.1 \mathrm{~m}^{3} \mathrm{~min}^{-1}$ with two custom-designed and fabricated MSP model 130 high-flow cascade impactors configured with Liu-Pui type omnidirectional inlets (Liu et al., 1983) that were deployed at the top of the tower. The calculated passing efficiency through the inlets for $20 \mu \mathrm{m}$-diameter particles was $95 \%$ and the $50 \%$ aerodynamic cut diameter between the two size factions was $0.8 \mu \mathrm{m}$ at ambient relative humidity (RH). Relative to MSP's Micro-Orifice Uniform Deposit Impactor (MOUDI) (Marple et al., 1991) that is in more widespread use by the research community, these hiflow impactors yield greater signal per unit deployment time while segregating aerosol size fractions using similar nozzle technology. Air volumes were measured with sharp-edged flow tubes and normalized to standard temperature and pressure $\left(0^{\circ} \mathrm{C}\right.$ and $\left.1 \mathrm{~atm}\right)$. One impactor was configured with quartz-fiber (Pallflex 2500 QAT-UP) substrates $(75 \mathrm{~mm}$ diameter) and back filters (90 $\mathrm{mm}$ diameter) for analysis of major ionic constituents and organic and elemental carbon (EC/OC). The other impactor was configured with Whatman 41 substrates and back filters for analysis of spectral absorption and insoluble aerosol mass. Analytical methods are described below. All data for samples were blank corrected based on analysis of impactor substrates and back filters that were deployed at the top of the tower and through which air was pulled only briefly $(\sim 15 \mathrm{~s})$. A paired set of blank impactors was exposed and processed approximately once every two weeks.

Impactors were cleaned with $18 \mathrm{M} \Omega \mathrm{cm}^{-1}$ deionized water (DIW), and dried, loaded, and unloaded in a Class 100 clean bench in a laboratory container at the base of the tower. The clean bench was configured with an activated charcoal scrubber on the inlet to remove reactive trace gases from feed air. After recovery, exposed samples were folded in half, sealed in polyethylene bags, and stored (and shipped) frozen prior to analysis. Samples and corresponding blanks were processed and analyzed using identical procedures.

Scattering coefficients at $530 \mathrm{~nm}$ for aerosols less than $10 \mu \mathrm{m}$ dry diameter (total $\sigma_{\mathrm{s}, 530}$ ) and less than $1 \mu \mathrm{m}$ dry diameter (sub- $\mu \mathrm{m} \sigma_{\mathrm{s}, 530}$ ) were measured continuously at one minute intervals by a Radiance Research 903M Integrating Nephelometer (Li et al., 1996). Scattering coefficients for the super $\mu \mathrm{m}$ size fraction were calculated by difference (super $\mu \mathrm{m} \sigma_{\mathrm{s}, 530}=$ total $\sigma_{\mathrm{s}, 530}-$ sub- $\left.\mu \mathrm{m} \sigma_{\mathrm{s}, 530}\right)$. Sample air was drawn though an omni directional inlet at the top of the tower and transmitted under laminar flow to the instrument at the base of the tower. The instrument was calibrated every other week with clean $\mathrm{CO}_{2}$ (Anderson and Ogren, 1998). The sampling sequence for the nephelometer was automatically switched among each of the two size-ranges and filtered air (to correct for Rayleigh scattering) for $20 \mathrm{~min}$ periods each. Data were not corrected for estimated truncation errors associated with forward scattering by large particles $(\mathrm{Li}$ et al., 1996). To facilitate direct comparison, scattering coefficients were averaged over periods of in-sector flow during which aerosols were sampled in parallel for characterization of ionic composition and spectral absorption.

From December 2007 through June 2009, direct solar irradiance under clear-sky conditions was measured continuously at 8 wavelengths between 340 and $1020 \mathrm{~nm}$ with a CIMEL Electronique Model 318A spectral radiometer deployed at the top of the tower as part of AERONET (e.g., Holben et al., 2001). Aerosol optical thickness (AOT) was calculated from spectral extinction of direct beam radiation at each wavelength based on the Beer-Bouguer Law. From March 2008 to June 2009, vertical profiles of aerosol extinction and backscatter and cloud heights were measured continuously with a micro pulse lidar deployed in one of the laboratory containers and operated as part of MPLNET (Welton et al., 1999; Reid et al., 2003). 


\subsection{Sample analysis}

Dichotomous aerosols sampled on quartz substrates and filters were shipped to and analyzed at the University of Virginia (UVA). Half sections were extracted under sonication in $6.0 \mathrm{ml}$ DIW and major ions (including $\mathrm{CH}_{3} \mathrm{COO}^{-}$, $\mathrm{HCOO}^{-},(\mathrm{COO})_{2}^{2-}, \mathrm{CH}_{3} \mathrm{SO}_{3}^{-}, \mathrm{SO}_{4}^{2-}, \mathrm{Cl}^{-}, \mathrm{Br}^{-}, \mathrm{NO}_{3}^{-}, \mathrm{NH}_{4}^{+}$, $\mathrm{Na}^{+}, \mathrm{K}^{+}, \mathrm{Mg}^{2+}$, and $\mathrm{Ca}^{2+}$ ) were analyzed by IC using procedures similar to those described by (Keene et al., 2009). $\mathrm{OC}$ and EC in quarter sections of samples were measured in triplicate by the transmission charring compensation technique (Birch and Cary, 1996) using a Sunset Laboratory, Inc. instrument. Data were not corrected for possible absorption of gas phase organics (e.g., Novakov et al., 2000) and thus represent upper limits. The remaining quarter sections were archived frozen.

Paired samples on Whatman 41 substrates and filters were shipped to the University of Miami (UM) for non-destructive analysis of spectral absorption $\left(\sigma_{\mathrm{a}, \lambda}\right)$. Light absorption between 300 to $1100 \mathrm{~nm}$ at $10 \mathrm{~nm}$ intervals with a $5 \mathrm{~nm}$ bandwidth was measured in triplicate with an Optronics OL 740A Spectroradiometer coupled to an OL 740-70 Diffuse Reflectance Attachment (DRA) (Ball et al., 2003; Aryal et al., 2013). The DRA is an integrating sphere through which a monochromatic light beam probes the sample. The diffuse reflectance technique is comparable to the optical reflectance method employed by Reid et al. (1998) except that the latter utilizes a broadband light source and does not use an integrating sphere to capture all of the reflected light. Because on-shore flow at Bermuda is not impacted by major nearfield emissions of organic aerosols or precursors from urban or industrial sources, potential artifacts associated with filter-based techniques (e.g., Lack et al., 2008) are assumed to be negligible. Following analysis of absorption, Whatman 41 substrates and filters were shipped to UVA where whole samples were extracted in three sequential 4 to $5 \mathrm{ml}$ aliquots of DIW, dried, and subsequently combusted at $500^{\circ} \mathrm{C}$. The residual mass of refractory particulate material (primarily mineral aerosol) was quantified gravimetrically (Savoie et al., 1992).

\subsection{Data quality and comparability}

Data for aerosol samples that corresponded to in-sector sampling times of less than $10 \%$ of a day $(2.4 \mathrm{~h})$ exhibited poor signal-to-noise for most analytes and were of questionable representativeness; these data were excluded from the final quality-assured data set. In addition, five samples contained unusually high concentration of sea-salt constituents $(30 \%$ to $380 \%$ higher than the sample with the next highest concentrations) and/or operator notes that suggested direct contamination by rainwater or splash; these samples were also excluded from the final quality-assured data set. The final database included results for 311 individual samples.
Detection limits (DLs) for all ionic constituents, EC/OC, and non-soluble aerosol mass were estimated following Keene et al. (1989). DLs for spectral absorption were estimated by propagating the minimum detectable reflectance $(0.5 \%)$ through the data reduction for each sample. In-sector collection times for samples included in the database varied from $10 \%$ to $100 \%$ of the corresponding daily deployment times. In addition, signal-to-noise varied among analytes. Consequently, DLs were calculated individually for each analyte in each sample and, thus, the numbers of detectable values varied among analytes. Analytical performance was verified by intercomparison of the UVA laboratory with UM and the University of New Hampshire, among others; routine analysis of audit solutions from the National Institute of Standards and Technology, the World Meteorological Organization, and the US Environmental Protection Agency; periodic analysis of standard additions to samples; and evaluation of ion balances and diagnostic ratios of analyte concentrations. These assessments indicate that the results are unbiased and precise to quantifiable levels.

The inlet for the impactor effectively passed bulk aerosol whereas the inlet for the nephelometer was configured with a $50 \%$ aerodynamic cut of $10 \mu \mathrm{m}$ dry diameter. For marine aerosol, this corresponds to a cut of approximately $20 \mu \mathrm{m}$ diameter at $80 \% \mathrm{RH}$. With the exception of high-wind conditions, most marine aerosol mass and scattering is associated with particles less than $20 \mu \mathrm{m}$ ambient diameter. Consequently, under most conditions encountered during this study, the upper end of the size distribution sampled with the impactor was approximately equal to that characterized by the nephelometer. Hereafter, the sub- $10 \mu \mathrm{m}$ size fraction sampled with the nephelometer will be referred to as bulk aerosol. In addition, the impactor segregated size fractions of aerosols hydrated to ambient RH at a $50 \%$ aerodynamic cut diameter of $0.8 \mu \mathrm{m}$, whereas the nephelometer segregated at $1.0 \mu \mathrm{m}$ dry diameter. Consequently, at the lower end of the ambient RH distribution $(<50 \% \mathrm{RH})$, the cut size for the dichotomous chemical and absorption data based on impactor sampling was about $0.2 \mu \mathrm{m}$ smaller than that for the corresponding scattering data and this difference increased with increasing ambient RH. Variability in the cut size between the two devices introduced some uncertainly in interpreting the paired dichotomous data but did not impact comparability of the summed (bulk) data. Potential influences of RH and aerosol hygroscopicity on the corresponding scattering and absorption coefficients (e.g., Wang et al., 2007; Lack et al., 2009) was not evaluated explicitly; reported values for dry aerosol are considered lower limits for ambient conditions.

Based on their thermodynamic properties (Henry's Law and dissociation constants), the equilibrium phase partition of $\mathrm{NH}_{3}, \mathrm{HNO}_{3}$, and $\mathrm{HCl}$ vary as functions of aerosol solution $\mathrm{pH}$, which in marine regions typically decreases with decreasing particle size (Keene et al., 2004). In addition, larger aerosol size fractions may be undersaturated with respect to the gas phase because of their smaller surface-to-volume 
ratios and relatively short atmospheric lifetimes against deposition (e.g., Keene et al., 2004). Consequently, $\mathrm{NH}_{4}^{+}, \mathrm{NO}_{3}^{-}$, and $\mathrm{Cl}^{-}$associated with bulk samples of chemically distinct marine aerosol size fractions are subject to possible artifact phase changes. Dichotomous sampling as employed for this study minimizes but does not eliminate the potential for such artifacts.

\subsection{Calculations}

Sea-salt and non-sea-salt constituents were differentiated following (Keene et al., 1986) for all samples for which the measured concentrations for the species of interest and the sea-salt reference species were greater than detection limits (DLs). As indicated above, super- and sub- $\mu \mathrm{m}$ aerosol size fractions were sampled on $75 \mathrm{~mm}$ and $90 \mathrm{~mm}$ diameter quartz-fiber substrates and filters, respectively. Background variability in concentrations of the two mostly commonly used sea-salt reference species $\left(\mathrm{Na}^{+}\right.$and $\left.\mathrm{Mg}^{2+}\right)$ differed between lots for the two filter sizes such that $\mathrm{Na}^{+}$ offered greater resolution in calculating nss concentrations associated with the super- $\mu$ m-diameter aerosol size fraction whereas $\mathrm{Mg}^{2+}$ offered greater resolution for those associated with the sub- $\mu \mathrm{m}$-diameter size fraction. Super- and sub$\mu \mathrm{m}$-diameter nss concentrations were calculated accordingly based on the composition of surface seawater reported by Wilson (1975).

Total mineral aerosol mass was calculated as 1.3 times the measured refractory ash mass based on Trapp et al. (2010b). The single scattering albedo (SSA) at $530 \mathrm{~nm}$ was calculated as the ratio of scattering to extinction $\left(\sigma_{\mathrm{s}, 530} /\left(\sigma_{\mathrm{s}, 530}+\sigma_{\mathrm{a}, 530}\right)\right)$. SSAs are reported for the subsets of samples for which both $\sigma_{\mathrm{s}, 530}$ and $\sigma_{\mathrm{a}, 530}$ were greater than DLs. Although $\sigma_{\mathrm{s}, 530}$ was above DLs during virtually all periods that the nephelometer was operational, $\sigma_{\mathrm{a}, 530}$ was below DLs in approximately $20 \%$ of the corresponding samples. Because the lower end of the $\sigma_{\mathrm{a}, 530}$ distribution was associated primarily to the upper end of the SSA distribution, sample statistics for SSAs are considered lower limits for ambient conditions. The absorption Ångström exponent (AAE) was calculated as the negative slope for a linear regression of the absorption coefficient versus wavelength between 400 to $800 \mathrm{~nm}$ on a log-log plot (Bergstrom et al., 2007). Only samples for which absorption was greater than DLs at all wavelengths were evaluated. For some samples, visual inspection indicated that the power-law wavelength dependence of absorption varied non-linearly consistent with relatively low correlation coefficients for the corresponding regressions. Variability in the AAE as a function of wavelength has also been reported elsewhere (see Bergstrom et al., 2007). For such cases, AAEs derived over the full wavelength range are not representative diagnostics for spectral dependence over that range. We included in this analysis only AAE values for which the correlation coefficients were greater than 0.5 and, thus, reasonably linear between 400 and $800 \mathrm{~nm}$.

For some evaluations, analyte concentrations associated with super- and sub- $\mu \mathrm{m}$-diameter aerosol size fractions were summed to yield bulk-aerosol concentrations. However, $\mathrm{Mg}^{2+}$ (together with other sea-salt species) and $\mathrm{NO}_{3}^{-}$were associated primarily with the super- $\mu \mathrm{m}$ size fraction $(97 \%$ and $97 \%$, respectively, based on median values for samples with detectable concentrations in both size fractions) and, consequently, corresponding concentrations of these analytes in the sub- $\mu$ m fraction were often below DLs ( $24 \%$ and $73 \%$, respectively, of all samples with detectable super- $\mu \mathrm{m}$ concentrations). Similarly, most $\mathrm{CH}_{3} \mathrm{SO}_{3}^{-}$, nss $\mathrm{SO}_{4}^{2-}$ and $\mathrm{NH}_{4}^{+}$was associated with the sub- $\mu \mathrm{m}$ fraction $(54 \%, 70 \%$, and $84 \%$, respectively, based on median values) and, consequently, corresponding concentrations of analytes in the super- $\mu \mathrm{m}$ fraction were sometimes below DLs $(13 \%, 2 \%$, and $20 \%$, respectively, of all samples with detectable sub- $\mu \mathrm{m}$ concentrations). For such cases, concentrations below DLs were assumed to be 0.0 and, thus, the summed values represent lower limits for total concentrations associated with ambient bulk aerosol.

\subsection{Atmospheric transport}

To evaluate influences of emissions in upwind source regions, a particle dispersion model FLEXPART (Stohl et al., 1998, 2005) was run in back trajectory mode (Stohl et al., 2003; Seibert and Frank, 2004). FLEXPART is driven with ECMWF analyzes and models transport using grid-resolved winds (at a resolution of 0.36 degrees, nominally $40 \mathrm{~km}$ at the equator) while accounting for sub-grid turbulence and deep convection. The result is an estimate of total column residence time over upwind regions, which can be displayed as a retroplume plot indicative of the column integrated contributions to sampled air from upwind regions. Starting at the tower height of $23 \mathrm{~m}$ above the surface and over the nominal sampling window from 15:00 UTC to 15:00 UTC each day, 40000 particles were released from the location of the measurement site and followed backward in time for 10 days. For each day, both the potential emission sensitivity retroplume, which is proportional to the particle column residence time over a given model grid cell, and the particle footprint residence time, which indicates the contribution from within the boundary layer of a given model grid cell, were calculated (Seibert and Frank, 2004; Stohl et al., 2003).

FLEXPART trajectories were classified into groups representing transport from major source regions based on fractional footprint residence times for each $24 \mathrm{~h}$ period over the duration of the study (all dates in the paper refer to the sample start date). Four source-region footprints were prescribed to delineate well-separated areas that were influenced predominantly by emissions from (1) the northeastern United States (NE US FP), (2) the southeastern United States and Gulf of Mexico (GULF FP), (3) Northern Africa and the 


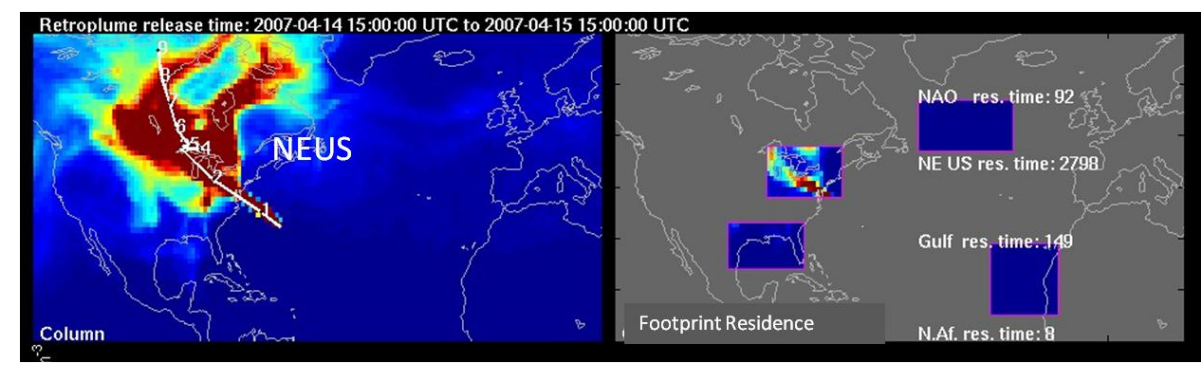

(a)

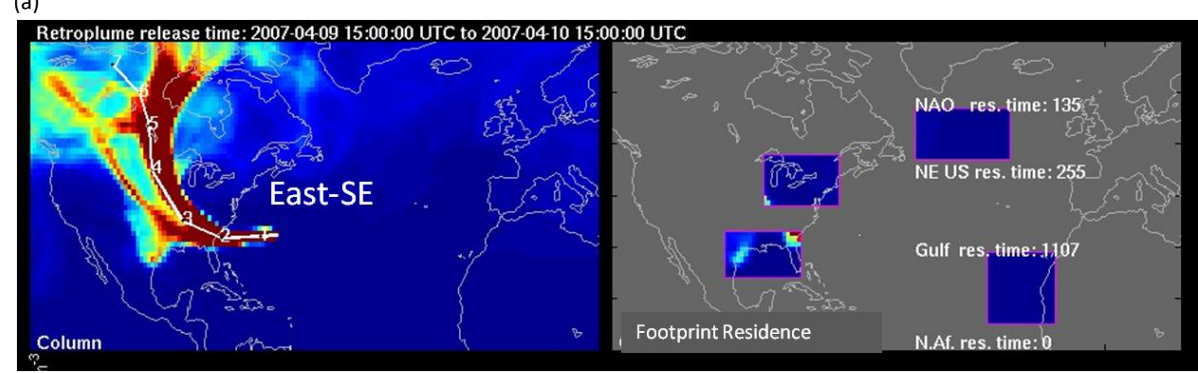

(b)

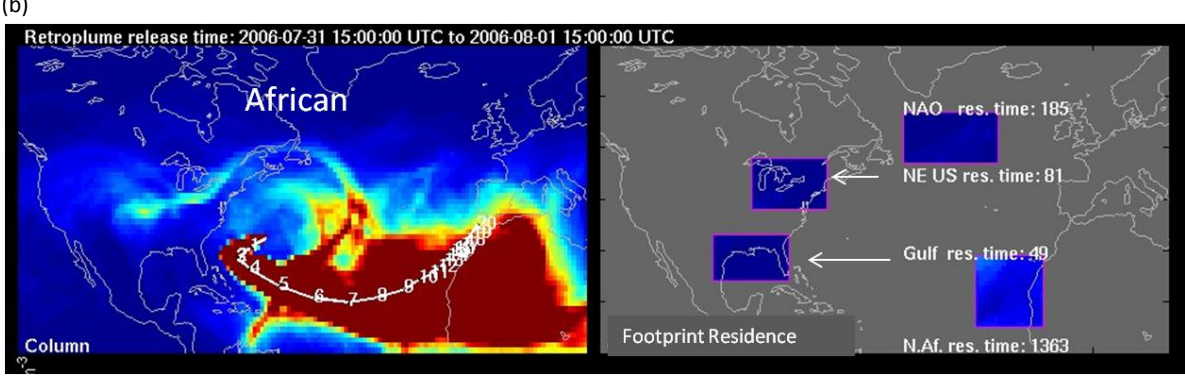

(c)

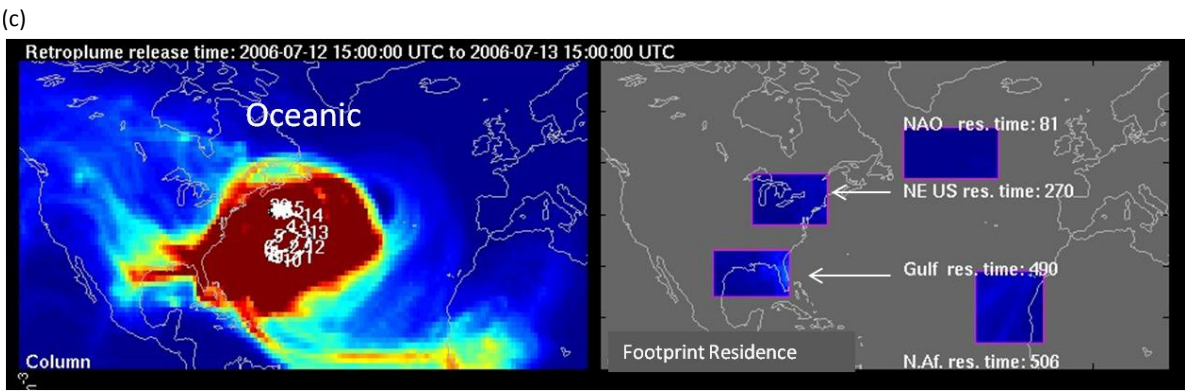

(d)

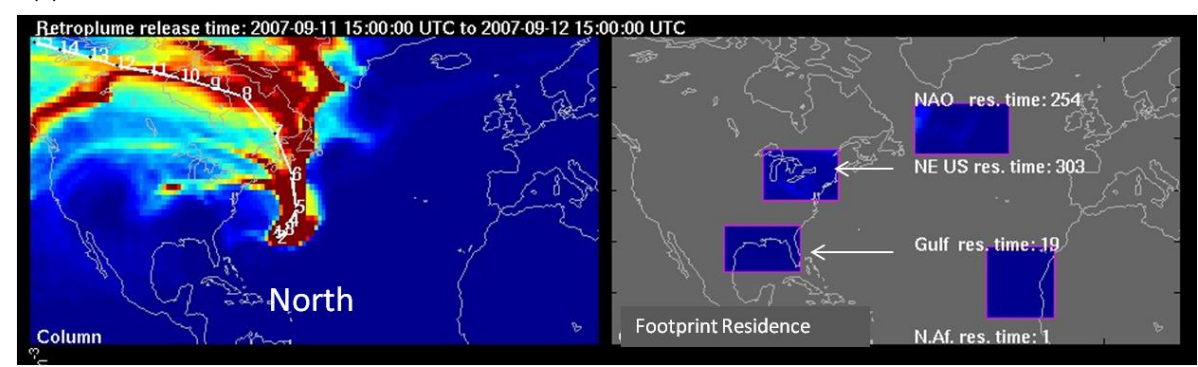

(e)

Fig. 1. Individual examples for each of the five aggregated source region flow patterns showing the column residence time for FLEXPART retroplumes (left panels) and the corresponding residence times in the four prescribed footprint source regions (NAO, NE US, Gulf, N.Af, in right panels) that were used to assign each day to a dominant source region delivering air to Bermuda: (a) NEUS on 21 to 22 April 2009 , (b) East-SEUS on 9 to 10 April 2007, (c) African (AFR) on 31 July to 1 August 2006, (d) oceanic on 12 to 13 July 2006, and (e) North on 11 to 12 September 2007. 
eastern tropical Atlantic (N.AF FP), and (4) the North Atlantic Ocean (NAO FP) (Fig. 1). The percent footprint residence time within each of these source regions relative to the total residence time within all four regions was then calculated for each $24 \mathrm{~h}$ period. Primary transport patterns were defined as those for which the fractional footprint residence time within one source region represented $75 \%$ or more of the total footprint residence time. Because only a subset of the days could be classified based on this criterion, the influences of combined source regions were also considered. These patterns were defined as those for which the combined fractional footprint residence times within two or three source regions represented $75 \%$ or more of the total residence time in all source regions.

The following criteria were used to classify atmospheric transport to Bermuda into five flow regimes based on the predominant source regions. The northeastern United States (NEUS) transport regime included days with $75 \%$ or more of the footprint residence times within the NE US FP region. The transport regime from the eastern United States and Gulf of Mexico (East-SEUS) included days with $75 \%$ or more of the footprint residence times within the GULF FP region and days when the combined residence times within the GULF FP and the NE US FP region accounted for $75 \%$ or more of total footprint residence times. This transport regime included contributions from sources in the eastern or southeastern United States and Gulf of Mexico region. The transport regime from North Africa and the tropical North Atlantic (AFR) included days with $75 \%$ or more of footprint residence times within the N.AF FP region and days when the combined residence times within the N.AF FP and one other secondary footprint region accounted for $75 \%$ or more of total residence times. The oceanic transport regime included days with $75 \%$ or more of footprint residence times within the NAO FP region, days when the combined residence times within the NAO FP and either the N.AF FP or the GULF FP regions accounted for $75 \%$ or more of the total residence times, and days for which the combined residence times within three footprint regions were required to account for $75 \%$ of the total residence time. The oceanic transport regime was generally associated with long trajectories over the ocean and anticyclonic flow around the Bermuda High (BH). Finally, the North transport regime included days when the combined residence times within the NAO FP and the NE US FP regions accounted for $75 \%$ or more of total residence times, indicative of transitions between clean marine and polluted urban origins over North America. After classifying all days based on fractional footprint residence times as detailed above, the corresponding chemical and physical properties of aerosols sampled on Bermuda over the three-year duration of the project were merged into a flow climatology.

\subsection{Statistical analysis}

Many of the aerosol parameters considered in this paper exhibit data distributions with significant deviations from normal. Therefore, medians were generally a better measure of the central tendency of populations, minimizing the potential influence of outliers. The significance of differences between designated categories such as season or transport regime were evaluated using non-parametric, or rank-based statistical tests. The Mann-Whitney two sample median test was used to discern differences in median values of individual aerosol chemical and physical parameters between two broad seasons, defined as the warm (April-September) and cool seasons (October-March). The Kruskal-Wallis analysis of variance test was employed to test the significance of differences in distributions of aerosol chemical and physical properties among transport regimes within each season.

\section{Results and discussion}

\subsection{Chemical and optical properties}

\subsubsection{Ionic composition}

Concentrations of $\mathrm{Na}^{+}, \mathrm{Mg}^{2+}, \mathrm{Cl}^{-}$, and $\mathrm{NO}_{3}^{-}$were above DLs in virtually all super- $\mu \mathrm{m}$ size fractions $(N \mathrm{~s}=301$ to 311 ; Table 1). Although, as noted above, concentrations in many paired sub- $\mu \mathrm{m}$ size fractions were less than DLs, the corresponding fractional contributions to total concentrations (super- + sub- $\mu \mathrm{m})$ were small $(2 \%$ to $12 \%$ based on median values), which implies that concentrations less DLs are a minor to negligible source of negative bias for the calculated bulk concentrations. Similarly, $\mathrm{nss}^{2--}, \mathrm{NH}_{4}^{+}$, and $\mathrm{CH}_{3} \mathrm{SO}_{3}^{-}$were greater than DLs in most sub- $\mu \mathrm{m}$ size fractions ( $N \mathrm{~s}=264$ to 309; Table 1). However, in contrast $\mathrm{Na}^{+}$, $\mathrm{Mg}^{2+}, \mathrm{Cl}^{-}$, and $\mathrm{NO}_{3}^{-}$, partitioned to a greater degree proportionately between the two size fractions and, consequently, their concentrations were greater than DLs in relatively larger numbers of paired super- $\mu \mathrm{m}$ size fractions (Table 1 ). This implies that super- $\mu \mathrm{m}$ concentrations of these analytes that were less than DLs were also relatively minor sources of negative bias for the calculated bulk concentrations. Because calculated concentrations of $n s s \mathrm{~K}^{+}$associated with the super- $\mu \mathrm{m}$ size fraction correspond to relatively small differences between substantially greater concentrations of total and seasalt $\mathrm{K}^{+}$(based on $\mathrm{Na}^{+}$), super- $\mu \mathrm{m}$ concentrations are poorly resolved. Only concentrations of sub- $\mu \mathrm{m} n \mathrm{~ns} \mathrm{~K}^{+}(N=171)$, are reported and interpreted.

Concentrations of major ionic constituents measured during this study (Table 1) are consistent with previously reported measurements of aerosol composition at Bermuda (Galloway et al., 1993; Turekian et al., 2001; Savoie et al., 2002) and with the longer term record of aerosol composition generated by the Atmosphere-Ocean Chemistry Experiment 
Table 1. Summary statistics for selected aerosol properties based on measured measured values $>$ DLs.

\begin{tabular}{|c|c|c|c|c|c|c|c|c|}
\hline Analyte & Nominal size, $\mu \mathrm{m}$ & Units & Median & Maximum & Minimum & Average & Standard deviation & $N$ \\
\hline \multirow[t]{3}{*}{$\mathrm{Na}^{+}$} & super & $\mathrm{nmol} \mathrm{m}^{-3}$ & 123 & 399 & 10 & 140 & 84 & 309 \\
\hline & sub & $\mathrm{nmol} \mathrm{m}^{-3}$ & 15 & 88 & 4 & 22 & 19 & 61 \\
\hline & bulk $^{1}$ & $\mathrm{nmol} \mathrm{m}^{-3}$ & 130 & 399 & 10 & 145 & 86 & 309 \\
\hline \multirow[t]{3}{*}{$\mathrm{Mg}^{2+}$} & super & $\mathrm{nmol} \mathrm{m}^{-3}$ & 11.7 & 44.2 & 0.03 & 13.8 & 9.7 & 301 \\
\hline & sub & $\mathrm{nmol} \mathrm{m}^{-3}$ & 0.4 & 3.6 & 0.02 & 0.5 & 0.4 & 230 \\
\hline & bulk $^{1}$ & $\mathrm{nmol} \mathrm{m}^{-3}$ & 12.0 & 44.2 & 0.03 & 14.2 & 9.8 & 301 \\
\hline \multirow[t]{3}{*}{$\mathrm{Cl}^{-}$} & super & $\mathrm{nmol} \mathrm{m}{ }^{-3}$ & 116 & 445 & 1 & 135 & 98 & 311 \\
\hline & sub & $\mathrm{nmol} \mathrm{m}^{-3}$ & 2 & 17 & 0.3 & 3 & 3 & 99 \\
\hline & bulk $^{1}$ & $\mathrm{nmol} \mathrm{m}^{-3}$ & 116 & 446 & 1 & 136 & 98 & 311 \\
\hline \multirow[t]{3}{*}{$\mathrm{NO}_{3}^{-}$} & super & $\mathrm{nmol} \mathrm{m}^{-3}$ & 13.8 & 63.8 & 0.5 & 16.6 & 11.0 & 308 \\
\hline & sub & $\mathrm{nmol} \mathrm{m}^{-3}$ & 0.5 & 6.0 & 0.1 & 1.0 & 1.2 & 82 \\
\hline & bulk $^{1}$ & $\mathrm{nmol} \mathrm{m}^{-3}$ & 14.0 & 68.9 & 1.2 & 16.8 & 11.2 & 308 \\
\hline \multirow[t]{3}{*}{ nss $\mathrm{SO}_{4}^{2-}$} & super & $\mathrm{nmol} \mathrm{m}^{-3}$ & 4.8 & 56.7 & $<0.0$ & 7.1 & 7.4 & 302 \\
\hline & sub & $\mathrm{nmol} \mathrm{m}^{-3}$ & 9.7 & 58.9 & 0.9 & 13.3 & 10.4 & 308 \\
\hline & bulk $^{2}$ & $\mathrm{nmol} \mathrm{m}{ }^{-3}$ & 15.7 & 105.6 & 0.9 & 20.3 & 16.4 & 308 \\
\hline \multirow[t]{3}{*}{$\mathrm{NH}_{4}^{+}$} & super & $\mathrm{nmol} \mathrm{m}^{-3}$ & 3.1 & 85.9 & 0.3 & 5.1 & 7.5 & 210 \\
\hline & sub & $\mathrm{nmol} \mathrm{m}^{-3}$ & 10.3 & 51.3 & 1.3 & 13.0 & 10.2 & 264 \\
\hline & bulk $^{2}$ & $\mathrm{nmol} \mathrm{m}^{-3}$ & 12.8 & 137.2 & 1.5 & 17.1 & 15.5 & 264 \\
\hline \multirow{3}{*}{$\mathrm{CH}_{3} \mathrm{SO}_{3}^{-}$} & super & $\mathrm{nmol} \mathrm{m}^{-3}$ & 0.210 & 0.941 & 0.019 & 0.245 & 0.177 & 270 \\
\hline & sub & $\mathrm{nmol} \mathrm{m}^{-3}$ & 0.213 & 1.61 & 0.001 & 0.264 & 0.202 & 309 \\
\hline & bulk $^{2}$ & $\mathrm{nmol} \mathrm{m}{ }^{-3}$ & 0.414 & 2.03 & 0.001 & 0.478 & 0.345 & 309 \\
\hline $\operatorname{nss~K}^{+}$ & sub & $\mathrm{nmol} \mathrm{m} \mathrm{m}^{-3}$ & 0.487 & 5.53 & 0.042 & 0.591 & 0.630 & 171 \\
\hline \multirow[t]{3}{*}{$\mathrm{OC}$} & super & $\mathrm{nmol} \mathrm{C} \mathrm{m}^{-3}$ & 33 & 399 & 1 & 49 & 60 & 157 \\
\hline & sub & $\mathrm{nmol} \mathrm{C} \mathrm{m}{ }^{-3}$ & 82 & 703 & 18 & 135 & 146 & 69 \\
\hline & bulk $^{3}$ & $\mathrm{nmol} \mathrm{C} \mathrm{m}{ }^{-3}$ & 130 & 916 & 23 & 203 & 202 & 54 \\
\hline \multirow[t]{3}{*}{$\mathrm{EC}$} & super & $\mathrm{nmol} \mathrm{C} \mathrm{m}{ }^{-3}$ & 5.2 & 48.1 & 0.5 & 7.3 & 8.4 & 33 \\
\hline & sub & $\mathrm{nmol} \mathrm{C} \mathrm{m}{ }^{-3}$ & 7.2 & 63.0 & 1.4 & 11.7 & 12.7 & 96 \\
\hline & bulk $^{3}$ & $\mathrm{nmol} \mathrm{C} \mathrm{m}{ }^{-3}$ & 13.1 & 80.3 & 2.4 & 20.6 & 18.9 & 23 \\
\hline Mineral & super & $\mu \mathrm{g} \mathrm{m}^{-1}$ & 5.7 & 43.5 & 1.5 & 8.8 & 7.5 & 57 \\
\hline \multirow[t]{2}{*}{ Aerosol } & sub & $\mu \mathrm{g} \mathrm{m}^{-1}$ & 6.7 & 27.5 & 0.9 & 9.2 & 7.0 & 46 \\
\hline & bulk $^{3}$ & $\mu \mathrm{g} \mathrm{m}^{-1}$ & 15.4 & 71.0 & 5.2 & 20.4 & 15.3 & 31 \\
\hline \multirow{3}{*}{$\sigma_{\mathrm{s}, 530}^{4}$} & super & $\mathrm{Mm}^{-1}$ & 4.6 & 23.1 & 0.3 & 5.8 & 4.1 & 170 \\
\hline & sub & $\mathrm{Mm}^{-1}$ & 9.7 & 62.1 & 1.9 & 11.9 & 9.1 & 173 \\
\hline & bulk $^{3}$ & $\mathrm{Mm}^{-1}$ & 16.1 & 68.7 & 2.9 & 17.7 & 10.8 & 170 \\
\hline \multirow[t]{3}{*}{$\sigma_{\mathrm{a}, 530}$} & super & $\mathrm{Mm}^{-1}$ & 0.154 & 1.30 & 0.001 & 0.223 & 0.209 & 263 \\
\hline & sub & $\mathrm{Mm}^{-1}$ & 0.478 & 2.70 & 0.000 & 0.556 & 0.436 & 291 \\
\hline & bulk $^{3}$ & $\mathrm{Mm}^{-1}$ & 0.697 & 3.56 & 0.047 & 0.813 & 0.597 & 244 \\
\hline \multirow[t]{3}{*}{$\mathrm{SSA}_{530}$} & super & - & 0.968 & 0.999 & 0.739 & 0.957 & 0.045 & 114 \\
\hline & sub & - & 0.958 & 0.998 & 0.575 & 0.947 & 0.051 & 137 \\
\hline & bulk $^{3}$ & - & 0.967 & 0.996 & 0.654 & 0.954 & 0.044 & 114 \\
\hline \multirow[t]{2}{*}{ AAE } & super & - & 1.31 & 4.91 & 0.17 & 1.53 & 1.02 & 116 \\
\hline & sub & - & 0.78 & 3.49 & 0.30 & 1.10 & 0.78 & 86 \\
\hline $\mathrm{AOT}_{500}^{5}$ & - & $\mathrm{Mm}^{-1}$ & 0.108 & 0.521 & 0.014 & 0.124 & 0.067 & 578 \\
\hline
\end{tabular}

${ }^{1}$ Sub- $\mu \mathrm{m}$ concentrations < DLs assumed equal to 0.0 (see text).

2 Super- $\mu$ m concentrations $<$ DLs assumed equal to 0.0 (see text).

3 Values for both size fractions $>$ DLs.

${ }^{4}$ Averaged daily over periods of in-sector flow during which aerosols were sampled for analysis of ionic composition and absorption.

5 Averaged daily (unsectored). 
(AEROCE) at THAO (J. Prospero, University of Miami, data available upon request). For example, based on the AEROCE record, the average annual concentrations of $\mathrm{Na}^{+}, \mathrm{NO}_{3}^{-}$, nss $\mathrm{SO}_{4}^{2-}, \mathrm{NH}_{4}^{+}$, and $\mathrm{CH}_{3} \mathrm{SO}_{3}^{-}$associated with aerosol sampled in bulk at the site between 1988 and 1997 were 160, 16.2, $20.9,17.5$, and 0.409 , respectively, which agree within $2 \%$ to $14 \%$ of the average concentrations reported herein (Table 1). Significant reductions in emissions of precursor $\mathrm{NO}_{\mathrm{x}}$ and $\mathrm{SO}_{2}$ over the US during this period contributed to the differences in particulate $\mathrm{NO}_{3}^{-}$and nss $\mathrm{SO}_{4}^{2-}$. A detailed evaluation of temporal trends in the ionic composition of aerosols and precipitation at Bermuda is reported in a companion paper currently in preparation (Keene et al., 2014). The corresponding partitioning of ionic constituents as a function of size is also consistent with reported aerosol size distributions measured at Bermuda (Turekian et al., 2001) and elsewhere in the North Atlantic marine boundary layer (MBL) (e.g., Huebert et al., 1996; Keene et al., 2004, 2009; Quinn and Bates, 2005). Differences between ambient size distributions of ionic species reflect the interplay among mixtures of aerosols from different source regions and source types (i.e., primary versus secondary, natural versus anthropogenic, marine versus continental), physical conditions (temperature, $\mathrm{RH}$ ), thermodynamics (i.e., the $\mathrm{pH}$ dependence in gasaerosol phase partitioning), size-dependent differences in atmospheric lifetimes against deposition, and air-mass history. Taken together, the above suggests that the ionic data generated by this project are representative of ambient-aerosol composition at Bermuda.

\subsubsection{EC/OC}

In contrast to the ionic data, relatively fewer concentrations of OC and EC (and of mineral aerosol mass) were greater than DLs (Table 1), which implies that the reported concentration ranges for these analytes are not representative of the lower portions of ambient concentration distributions. In addition, the exposed portion of the impaction substrates on which super- $\mu \mathrm{m}$ aerosols were sampled was a factor of 2.8 smaller than that for the back-up filters on which sub- $\mu \mathrm{m}$ aerosols were sampled. Because the analytical technique for EC/OC quantifies loadings based on a standard unit area of material punched from exposed samples, analytical resolution (signal-to-noise) for the super- $\mu \mathrm{m}$ size fraction was a factor of about 2.8 greater on average than the sub- $\mu \mathrm{m}$ size fraction. Consequently, some caution and an appreciation of potential limitation are warranted when interpreting these data.

Despite the above caveats, concentrations of size-resolved OC during this study (Table 1) are within the range of those associated with size-resolved aerosol at THAO during spring (average concentrations summed over the super- and sub$\mu \mathrm{m}$ size fractions of 33.9 and $76.6 \mathrm{nmol} \mathrm{C} \mathrm{m}^{-3}$, respectively; Turekian et al., 2003). Although the ranges overlap, the average concentration of sub- $\mu \mathrm{m}$ OC reported herein (Table 1) is about a factor of two less than those measured in the western North Atlantic MBL under conditions of North American outflow during TARFOX (average of $488 \mathrm{nmol} \mathrm{C} \mathrm{m}^{-3}$ ) and NEAQS (average of $375 \mathrm{nmol} \mathrm{C} \mathrm{m}^{-3}$ ) (Quinn and Bates, 2005). The average concentration of super- $\mu \mathrm{m}$ OC (Table 1) is also somewhat less than the corresponding average reported for NEAQS $\left(62 \mathrm{nmol} \mathrm{C} \mathrm{m}^{-3}\right)$. In contrast, the average concentration of sub- $\mu \mathrm{m}$ OC at Bermuda (Table 1) is greater than those measured during several campaigns in the eastern and tropical North Atlantic MBL (less than $\sim 80 \mathrm{nmol} \mathrm{C} \mathrm{m}^{-3}$ ) (O’Dowd et al., 2004; Quinn and Bates, 2005). Similarly, the average concentration of sub- $\mu \mathrm{m} \mathrm{EC}$ at Bermuda (Table 1) is less than those for EC associated with North American outflow during NEAQS $\left(36 \mathrm{nmol} \mathrm{m}^{-3}\right)$ and TARFOX $\left(67 \mathrm{nmol} \mathrm{m}^{-3}\right)$ and greater than the eastern and tropical North Atlantic MBL ( $<8$ to $15 \mathrm{nmol}$ to $15 \mathrm{nmol} \mathrm{m}^{-3}$, respectively) (Quinn and Bates, 2005).

\subsubsection{Mineral aerosol}

Based on a mass ratio of 9.6 for residual refractory ash to $\mathrm{Al}$ in the tropical North Atlantic MBL $\left(N=1349 ; r^{2}=0.95\right.$; D. L. Savoie, and R. Arimoto, personal communication, 2004) and the mass ratio of 1.3 for mineral aerosol to ash (Trapp et al., 2010b), the average mineral aerosol mass for bulk aerosol with concentrations greater than DLs (Table 1) is about 25 times greater than those inferred from the average annual concentrations of crustal $\mathrm{Al}$ measured daily at THAO between 1988 and 1990 (0.044 to $0.056 \mu \mathrm{g} \mathrm{Al} \mathrm{m}{ }^{-3}$; Arimoto et al., 1995). This large difference reflects the fact that residual aerosol masses for most samples during our study were less than DLs (only larger dust outbreaks were detectable). In contrast, greater sample volumes (factor of about 10), bulk (versus dichotomous) sampling, and greater analytical resolution afforded by neutron activation analysis yielded detectable $\mathrm{Al}$ in virtually all samples analyzed by Arimoto et al. (1995). However, the average bulk mineral mass based on our data (Table 1) was about the same as that inferred from the average for $\mathrm{Al}$ measured by Arimoto et al. (1995) during periods of easterly flow $\left(1.26 \mu \mathrm{g} \mathrm{Al} \mathrm{m}{ }^{-3}\right.$ or $15.6 \mu \mathrm{g}$ dust $\left.\mathrm{m}^{-3}\right)$. As discussed in more detail below, the larger dust events, which accounted for the upper ends of the concentrations distributions at Bermuda during both studies, were typically associated with atmospheric transport from North Africa. Relative to Bermuda, the efficient transport of dust by the trade wind regime sustains substantially higher average and peak concentrations of mineral aerosol across the tropical North Atlantic Ocean including the MBL and free troposphere at Puerto Rico (Reid et al., 2003), the MBL at Barbados (Arimoto et al., 1995; Trapp et al., 2010a), the central MBL (Bates et al., 2001), and the free troposphere at Tenerife (Maring et al., 2000). 


\subsubsection{Scattering coefficient}

Relative to the ionic data, intermittent malfunction of the nephelometer resulted in fewer days during which scattering coefficients were measured in parallel (Table 1). Total scattering at Bermuda was within the range measured at Barbados during periods of low to moderate dust concentrations (less than $40 \mu \mathrm{g} \mathrm{m}^{-3}$ ) using an identical instrument (10 to $42 \mathrm{Mm}^{-1}$; ( $\mathrm{Li}$ et al., 1996). Because scattering varies as a function of wavelength and $\mathrm{RH}$, our results cannot be directly compared on a quantitative basis with those measured at different wavelengths and RHs or, in some cases, as adjusted to ambient RHs. Qualitatively, measurements of $\sigma_{\mathrm{s}, 530}$ at less than $40 \%$ RH for bulk aerosol at Bermuda (Table 1) fall within the lower ends of ranges measured at $550 \mathrm{~nm}$ and $55 \%$ RH during various campaigns in the North Atlantic MBL (Quinn and Bates, 2005; Sierau et al., 2006). The fine fraction of scattering (sub- $\mu \mathrm{m} \sigma_{\mathrm{s}, 530}$ divided by total $\sigma_{\mathrm{s}, 530}$ ) based on average values at Bermuda (0.67) is within the range of averages at $550 \mathrm{~nm}$ and $55 \% \mathrm{RH}$ reported for different air-mass types sampled in the Gulf of Maine off the northeastern US coast during ICARTT (0.64 to 0.78; (Sierau et al., 2006). The fine fraction of scattering at Bermuda also overlaps the range measured at $550 \mathrm{~nm}$ and $55 \% \mathrm{RH}$ over the eastern North Atlantic under conditions of European outflow during ACE-2 (average of 0.56 Quinn and Bates, 2005).

\subsubsection{Absorption coefficient and AAE}

The average absorption coefficient at $530 \mathrm{~nm}$ and less than $40 \% \mathrm{RH}$ for bulk aerosol at Bermuda (Table 1) is a factor of 7 less than those at $550 \mathrm{~nm}$ and $55 \% \mathrm{RH}$ in North American outflow during TARFOX and NEAQS and a factor of 5 less than that at $530 \mathrm{~nm}$ and $55 \%$ RH during ICARTT. However, absorption at Bermuda falls within the range of values reported for the eastern and tropical North Atlantic (Quinn and Bates, 2005). In contrast to these other campaigns which report no measurable absorption by larger aerosols in the North Atlantic MBL, super- $\mu \mathrm{m}$ aerosol accounted for about $25 \%$ of the median and average total absorption at Bermuda during our study (Table 1). We infer that the greater analytical resolution afforded by direct measurement as used here relative to calculating proportionately small contributions by subtraction (total absorption - sub- $\mu$ m absorption) as employed in the other studies contributed to these differences.

The average AAE for super- $\mu \mathrm{m}$ and sub- $\mu \mathrm{m}$ size fractions (Table 1) fell within the range of AAEs for selected cases from different field campaigns in the NAO and elsewhere reported by Bergstrom et al. (2007). The corresponding ranges in values were also similar to those measured during the Gulf of Mexico Atmospheric Composition and Climate Study (Bergstrom et al., 2007). AAE values of about 1.0 indicate relatively little variability in absorption as a function of wavelength and are generally associated with urban pollution plumes, in which absorption is dominated by combustion- derived light-absorbing carbon. Higher AAEs indicate relatively greater absorption at shorter wavelengths and are generally associated with absorption by organic carbonaceous (also referred to as brown carbon) and/or mineral aerosol constituents. AAE values less than 1.0 may result from variability in the imaginary part of the index of refraction as a function of wavelength and/or random measurement uncertainty. To evaluate the sensitivity of these population statistics to the prescribed cutoff threshold of 0.5 for the correlation coefficient (discussed in Sect. 2.4), we evaluated statistics based on a higher cut off of 0.7. The resulting average and median values for the sub- $\mu \mathrm{m}$ AAE increased from 1.10 to 1.23 and from 0.78 to 0.88 , respectively, and the numbers of samples above the threshold decreased from 86 to 56 . These differences were driven primarily by the removal of disproportionately larger numbers of samples associated with westerly flow from North America which, as discussed in more detail below, exhibited relatively lower AAEs. We return to this point below.

\subsubsection{Single scattering albedo and aerosol optical thickness}

The single scattering albedos (SSA) for sub- $\mu \mathrm{m}$ and bulk aerosol at $530 \mathrm{~nm}$ and less than $40 \% \mathrm{RH}$ measured at Bermuda (Table 1) fall within the ranges of values measured elsewhere in the North Atlantic MBL (Quinn and Bates, 2005; Sierau et al., 2006). Mean SSA for sub- $\mu$ m aerosol was $1 \%$ less than that for bulk aerosol, which is also within the range of average differences at $550 \mathrm{~nm}$ and $55 \% \mathrm{RH}$ observed elsewhere. Although the ranges overlap, the average AOT at $500 \mathrm{~nm}$ at Bermuda (Table 1) is lower than those for other regions in the North Atlantic, which vary from 0.18 at $525 \mathrm{~nm}$ in the eastern basin to 0.38 at $405 \mathrm{~nm}$ in North American outflow during TARFOX (Quinn and Bates, 2005; Sierau et al., 2006).

\subsubsection{Summary evaluation}

Based on evaluation of data quality and size-resolved composition, comparisons with past measurements at Bermuda, and comparison with measurements in surrounding regions of the NAO MBL and elsewhere, the above assessment indicates that the ionic composition and optical properties of dichotomous and bulk aerosols reported herein are reasonably representative of the western NAO MBL at Bermuda during the period of the study. Although measurements of mineral aerosol mass, OC, and EC fall within the ranges of values measured previously on Bermuda and elsewhere over the NAO, concentration distributions are truncated and do not include the lower ends of the concentration distributions for ambient aerosols. Consequently, sample statistics for these analytes are not representative of regional conditions. However, those data are reliable, provide quantitative constraints for the upper portions of concentration distributions, and, as 
indicated below, are useful for diagnosing relevant characteristics of individual events.

\subsection{Seasonal variability}

Seasonal differences in source strengths, chemical processing, and atmospheric transport all contribute to variability in aerosol chemical and physical properties. The significance of differences in distributions of aerosol properties between the warm and cool seasons and among transport regions within each season are depicted in Table 2. Two asterisks indicate $95 \%$ confidence in rejecting the null hypothesis that the measured distributions of each variable correspond to random selections from the same population; one asterisk implies $90 \%$ confidence in rejecting the null hypothesis. The season with the higher median concentration of each parameter that exhibits a significant difference is indicated with a " $\mathrm{w}$ " for warm or a "c" for cool.

We appreciate that this relatively coarse seasonal partitioning may not adequately characterize temporal variability within seasons. For example, when data are binned by month, the maximum median monthly nss $\mathrm{SO}_{4}^{2-}$ and $\mathrm{NO}_{3}^{-}$ concentrations ( 27.0 and $30.1 \mathrm{nmol} \mathrm{m}^{-3}$, respectively) were during May and the minimum (12.5 and $9.3 \mathrm{nmol} \mathrm{m}^{-3}$, respectively) during July and September, respectively. All of these maximum and minimum monthly medians fell within the warm season. However, when data within each season were further partitioned into five transport regimes (see below), the numbers of observations for each regime were relatively low, which limited the power of associated statistical tests. In addition, as described in more detail below, much of the temporal variability in aerosol characteristics within each season was driven by changes in large-scale atmospheric transport and the associated source regions for aerosols and precursors during that season. For example, the peak median values for nss $\mathrm{SO}_{4}^{2-}$ and $\mathrm{NO}_{3}^{-}$during May were associated primarily with efficient westerly transport from North America, which is more prevalent after spring frontal passages whereas the minimum medians during summer were associated primarily with southeasterly transport around the Bermuda High, which is more prevalent during summer. The relatively coarse seasonal partitioning adopted herein represents a compromise between evaluating seasonal versus transport-related variability based on the finite data set summarized in Table 1.

\subsubsection{Cool season}

Relative to the warm season, air sampled between October and March was, on average, colder, drier, and associated with higher wind speeds, higher pressures and more northerly transport (Table 3). Stronger winds generated higher sea-salt concentrations $\left(\mathrm{Na}^{+}, \mathrm{Mg}^{2+}\right.$, and associated constituents). EC associated with the sub-micron size fraction was also relatively higher during these months.

\subsubsection{Warm season}

Air sampled between April and September was associated with overall warmer conditions and correspondingly higher relative humidity and lower atmospheric pressure (Table 3 ). Concentrations of nss $\mathrm{SO}_{4}^{2-}$ and $\mathrm{CH}_{3} \mathrm{SO}_{3}^{-}$associated with bulk aerosol, nss- $\mathrm{Ca}^{2+}$ and nss $\mathrm{SO}_{4}^{2-}$ associated with the super- $\mu \mathrm{m}$ size fraction and scattering by the sub- $\mu \mathrm{m}$ size fraction were significantly higher during this season. In addition, the corresponding influences of aerosols on columnintegrated aerosol optical depth based on both downward observations of backscattering at $550 \mathrm{~nm}$ from the ModerateResolution Imaging Spectroradiometer (MODIS AOD 550 ) and upward observations of scattering at $500 \mathrm{~nm}$ from the AERONET CIMEL instrument $\left(\mathrm{AOT}_{500}\right)$ were also significantly greater. However, many analytes including $\mathrm{NO}_{3}^{-}$, $\mathrm{NH}_{4}^{+}$, nss $\mathrm{K}^{+}, \mathrm{OC}$, and mineral aerosol did not differ significantly between these two broad seasons.

Although seasonal differences accounted for some of the measured variability for individual analytes, all exhibited substantial variability within each season. To investigate the nature of this residual variability, aerosol chemical and optical properties within each season were evaluated as a function of transport history based on the flow climatology constructed from FLEXPART retroplumes and footprint residence times. This information was used to characterize the influence of source region on the chemical and optical properties of the sampled air masses.

\subsection{Transport climatology}

\subsubsection{Transport patterns}

Figure 1a-f depicts examples of the five transport patterns defined above. Each example illustrates the column residence time retroplume in the left panel, and the contribution of footprint residence time from the designated source regions in the right panel. This flow pattern classification scheme characterizes major features of the transport climatology to Bermuda. The advance of continental air from North America to Bermuda is driven by the transient passage of low pressure systems. Cyclonic flow patterns are associated with frontal passages, and subsequent post-frontal flow. As these low pressure systems are pushed off shore by advance of a continental high, the origin of air masses on Bermuda that arrive from the US becomes more northerly. Anticyclones that advance to a location east of Bermuda eventually result in flow becoming more southerly, with trajectories that arrive from the southeast or the southwest around the semipermanent feature of the $\mathrm{BH}$. These $\mathrm{BH}$ conditions result in roughly equivalent and relatively short residence times over each of the prescribed source regions; most of the time, air resides over the open ocean. However, when the high is large and persistent, air masses with a significant influence from African source regions are transported to Bermuda. 
Table 2. Results of non-parametric statistical tests on distributions of aerosol composition, radiative characteristics, and meteorological conditions during sampling, compared across season, and between flow patterns within each season.

\begin{tabular}{|c|c|c|c|c|c|}
\hline \multirow{2}{*}{$\begin{array}{l}\text { Type } \\
\text { Bulk }\end{array}$} & \multicolumn{2}{|c|}{ Parameter size fraction } & \multirow{2}{*}{$\begin{array}{c}\begin{array}{c}\text { Distributions } \\
\text { by season }\end{array} \\
*{ }^{*} \mathrm{c}\end{array}$} & \multirow{2}{*}{$\begin{array}{l}\text { Distributions by transport } \\
\text { patterns: cool (Oct-Mar) }\end{array}$} & \multirow{2}{*}{$\begin{array}{l}\begin{array}{l}\text { Distributions by transport } \\
\text { patterns: warm (Apr-Sep) }\end{array} \\
* *\end{array}$} \\
\hline & $\mathrm{Na}^{+}$ & bulk $^{1}$ & & & \\
\hline aerosol & $\mathrm{Mg}^{2+}$ & bulk $^{1}$ & ${ }^{* *} \mathrm{c}$ & - & - \\
\hline \multirow[t]{4}{*}{ chemical composition } & $\mathrm{Cl}^{-}$ & bulk $^{1}$ & $* * \mathrm{c}$ & - & - \\
\hline & $\mathrm{NO}_{3}^{-}$ & bulk $^{1}$ & - & $* *$ & $* *$ \\
\hline & $\mathrm{NH}_{4}^{+}$ & bulk $^{2}$ & - & $* *$ & $* *$ \\
\hline & $\mathrm{CH}_{3} \mathrm{SO}_{3}^{-}$ & bulk $^{1}$ & $* * \mathrm{~W}$ & $* *$ & - \\
\hline \multirow{14}{*}{$\begin{array}{l}\text { Size-resolved } \\
\text { aerosol } \\
\text { chemical composition }\end{array}$} & $\mathrm{nss} \mathrm{SO}{ }_{4}^{2-}$ & super & $* *{ }_{\mathrm{W}}$ & - & $* *$ \\
\hline & & sub & - & $* *$ & $* *$ \\
\hline & & bulk $^{2}$ & ${ }^{* *} \mathrm{w}$ & $* *$ & $* *$ \\
\hline & $\mathrm{nss} \mathrm{K}^{+}$ & sub & - & _- & * \\
\hline & nss $\mathrm{Ca}^{2+}$ & super & $* *{ }_{\mathrm{W}}$ & $* *$ & $* *$ \\
\hline & OC & super & - & - & $*$ \\
\hline & & sub & - & - & - \\
\hline & & bulk $^{3}$ & - & - & - \\
\hline & EC & super & - & - & - \\
\hline & & sub & $*_{\mathrm{c}}$ & $* *$ & $* *$ \\
\hline & & bulk $^{3}$ & $*_{\mathrm{c}}$ & - & - \\
\hline & Mineral & super & - & - & * \\
\hline & Aerosol & sub & - & $* *$ & - \\
\hline & & bulk ${ }^{3}$ & - & $* *$ & - \\
\hline \multirow{13}{*}{$\begin{array}{l}\text { Aerosol physical/ } \\
\text { radiative } \\
\text { properties }\end{array}$} & $\sigma_{\mathrm{s} 530}^{4}$ & super & - & $* *$ & $* *$ \\
\hline & & sub & ${ }^{*} \mathrm{w}$ & - & $* *$ \\
\hline & & bulk $^{3}$ & - & - & $* *$ \\
\hline & $\sigma_{\mathrm{a}, 530}$ & super & - & - & $* *$ \\
\hline & & sub & - & - & $* *$ \\
\hline & & bulk $^{3}$ & - & - & $* *$ \\
\hline & $\mathrm{SSA}_{530}$ & super & - & - & - \\
\hline & & sub & - & - & $* *$ \\
\hline & & bulk $^{3}$ & - & - & - \\
\hline & AAE & super & - & - & $* *$ \\
\hline & & sub & - & - & $* *$ \\
\hline & $\mathrm{AOT}_{500}^{5}$ & & $* *{ }_{\mathrm{W}}$ & - & $* *$ \\
\hline & $\mathrm{AOD}^{6}$ & & ${ }^{* *} \mathrm{~W}$ & $* *$ & $* *$ \\
\hline \multirow{5}{*}{$\begin{array}{l}\text { Meteorological } \\
\text { conditions }\end{array}$} & avgT & & $* *{ }_{\mathrm{W}}$ & $* *$ & $* *$ \\
\hline & avgRH & & ${ }^{* *} \mathrm{~W}$ & $* *$ & $* *$ \\
\hline & avgWS & & $* * \mathrm{c}$ & & - \\
\hline & avgWDir & & $* * \mathrm{c}$ & $* *$ & $* *$ \\
\hline & avgPr & & $* * \mathrm{c}$ & & $* *$ \\
\hline
\end{tabular}

* $p=0.10$, significant at $90 \%$

** $p=0.05$, significant at $95 \%$;

${ }^{1}$ Sub- $\mu \mathrm{m}$ concentrations < DLs assumed equal to 0.0 (see text).

2 Super- $\mu \mathrm{m}$ concentrations $<$ DLs assumed equal to 0.0 (see text).

${ }^{3}$ Values for both size fractions $>$ DLs.

4 Averaged daily over periods of in-sector flow during which aerosols were sampled for analysis of ionic composition and absorption.

5 Averaged daily (unsectored).

${ }^{6}$ AOD is regional satellite value derived from MODIS.

\subsubsection{Transport pattern frequency}

The frequencies of flow patterns for air arriving at Bermuda vary between warm and cool seasons (Moody and Galloway, 1988). The FLEXPART model was run for every $24 \mathrm{~h}$ period between 1 July 2006 and 30 June 2009 and the frequencies for each flow pattern over all days during each season are depicted in Fig. 2a and b. Cool season frontal passages and post frontal transport, which favor the transport of North American air from the NEUS and East-SEUS, accounted for $49 \%$ 

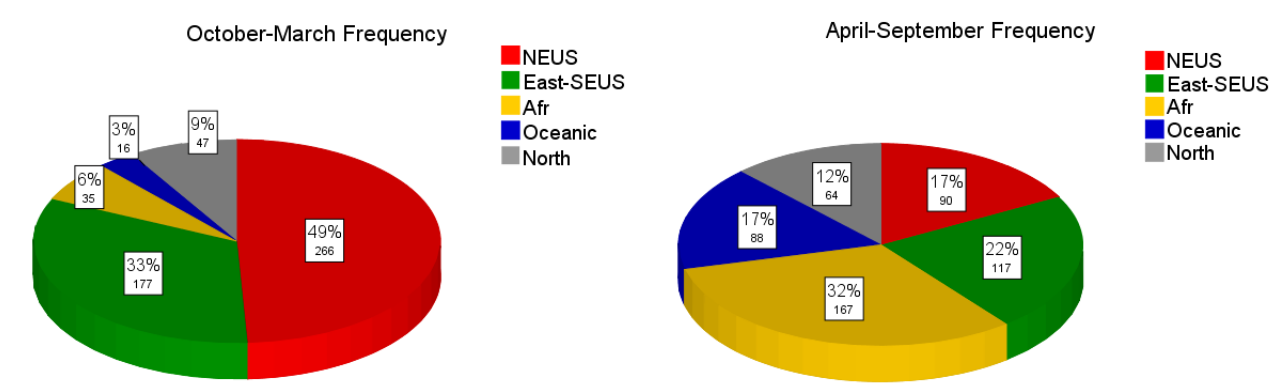

(a)

(c) (b)

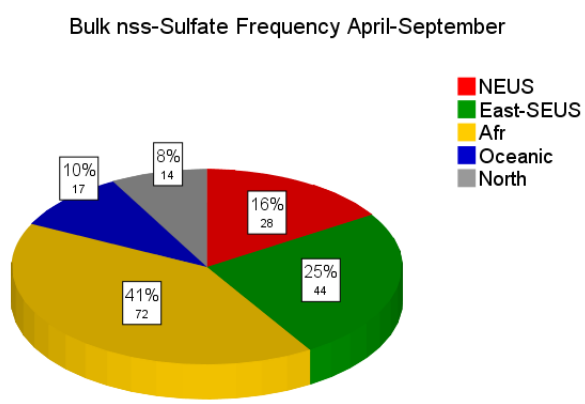

(d)

Fig. 2. Transport regime frequencies based on all days during the $3 \mathrm{yr}$ duration of the project for (a) the cool season, October through March and (b) the warm season, April through September. Corresponding transport frequencies based on the subset of all days for which nss $\mathrm{SO}_{4}^{2-}$ data were available during the (c) cool season and (d) warm season.

Table 3. Meteorological conditions recorded during sectored (sampling) flow periods. Seasonal average conditions and the average conditions associated with each FLEXPART defined flow pattern.

\begin{tabular}{llllllll}
\hline \multirow{2}{*}{ Season } & Parameter & \multicolumn{5}{c}{ Air mass origin based on transport classification } \\
& & Total & NEUS & East-SEUS & African & Oceanic & North \\
\hline \multirow{2}{*}{ Cool } & $\operatorname{avg}\left({ }^{\circ} \mathrm{C}\right)$ & 19.0 & 18.4 & 19.6 & 20.4 & 21.5 & 16.8 \\
& $\operatorname{avgRH}(\%)$ & 69 & 64 & 73 & 82 & 81 & 66 \\
& $\operatorname{avgWS}(\mathrm{kt})$ & 5.3 & 4.9 & 5.9 & 4.8 & 5.3 & 4.9 \\
& $\operatorname{avgWDir}\left({ }^{\circ}\right)$ & 260 & 265 & 254 & 243 & 244 & 276 \\
& $\operatorname{avgPr}(\mathrm{hPa})$ & 1016 & 1016 & 1015 & 1015 & 1019 & 1018 \\
Warm & $\operatorname{avgT}\left({ }^{\circ} \mathrm{C}\right)$ & 22.6 & 20.1 & 22.4 & 24.3 & 22.6 & 20.4 \\
& $\operatorname{avgRH}(\%)$ & 77 & 69 & 78 & 80 & 76 & 75 \\
& $\operatorname{avgWS}(\mathrm{kt})$ & 4.5 & 4.3 & 4.8 & 4.3 & 4.4 & 4.6 \\
& $\operatorname{avgWDir}\left({ }^{\circ}\right)$ & 248 & 260 & 255 & 239 & 237 & 259 \\
& $\operatorname{avgPr}(\mathrm{hPa})$ & 1014 & 1016 & 1013 & 1014 & 1016 & 1014 \\
\hline
\end{tabular}

and $33 \%$, respectively, of flow during all days; transport around the $\mathrm{BH}$ represented $9 \%$ of the flow; and transitional flow from the North accounted for the balance (Fig. 2a). During the warm season, transport around the $\mathrm{BH}$ was the dominant feature with $49 \%$ of the flow associated with an African or oceanic source region (Fig. 2b). Only $39 \%$ of the transport was classified as having a significant contribution from the US (17\% NEUS, $22 \%$ East-SEUS), and the mixed influence of flow from the North occurred $12 \%$ of the time. These results reflect large-scale seasonal changes in the position and strength of the Bermuda High, and the 

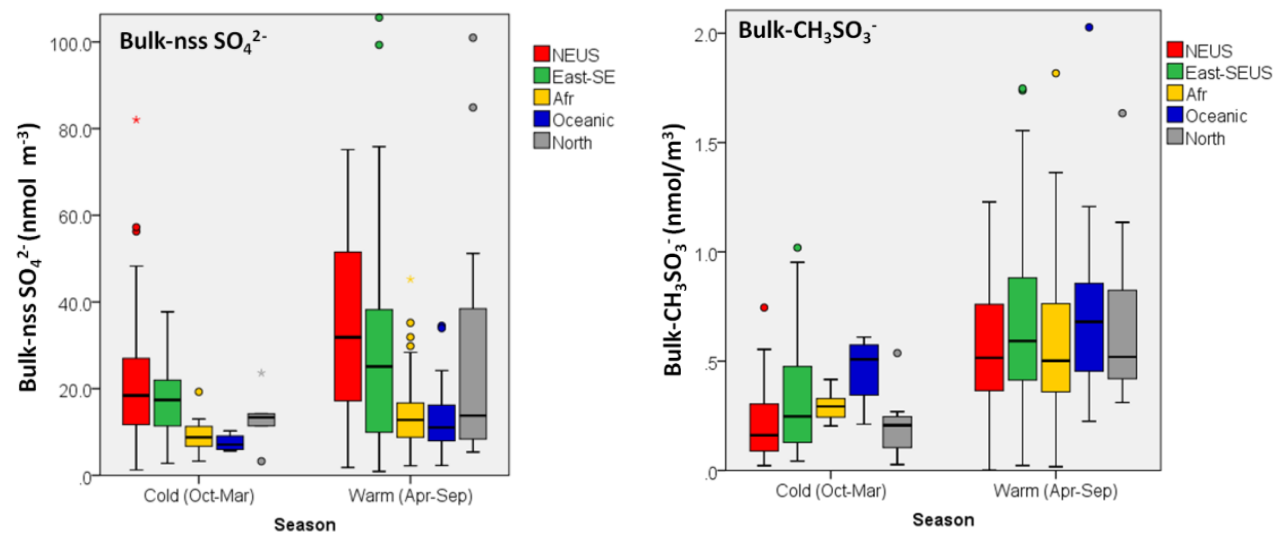

(a)

(b)
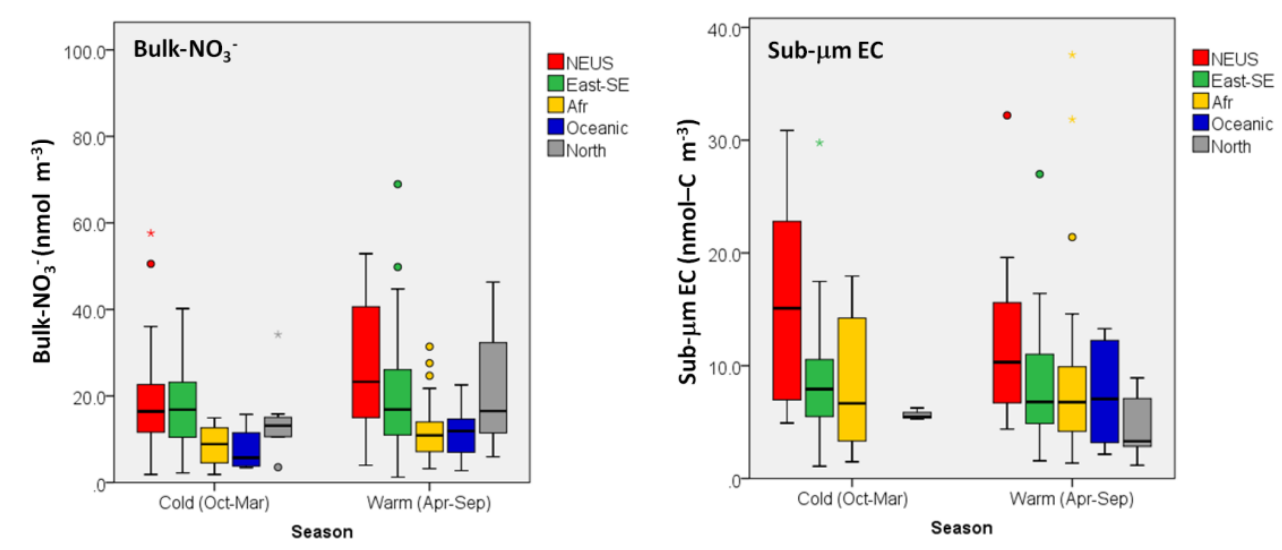

(c)

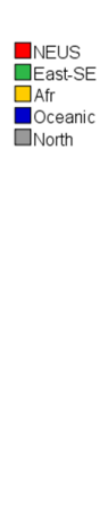

(d)

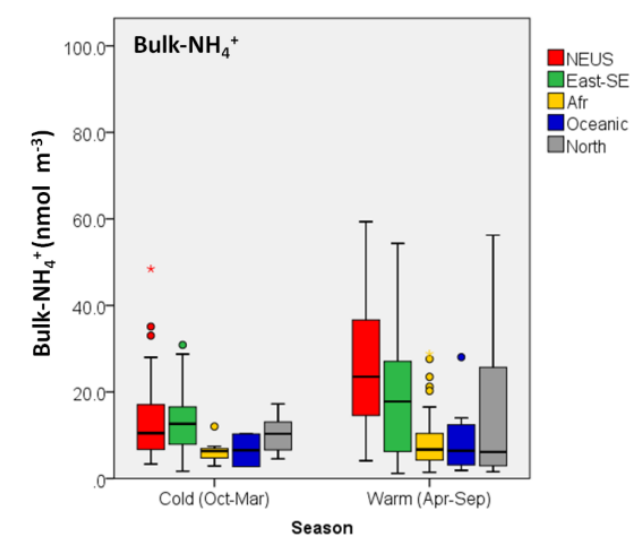

(e)

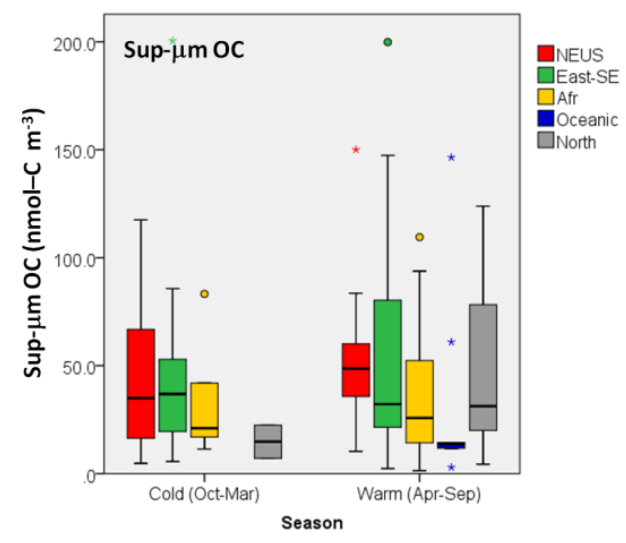

(f)

Fig. 3. Box and whisker plots depicting the 10th, 25th, 50th, 75th, and 90th percentiles and outliers (plotted individually with circles for 1.5 times the interquartile range, with asterisks for outliers 3 times the interquartile range) for (a) bulk $\mathrm{nss}_{4} \mathrm{SO}_{4}^{2-}$, (b) bulk $\mathrm{CH}_{3} \mathrm{SO}_{3}^{-}$, (c) bulk $\mathrm{NO}_{3}^{-}$, (d) sub- $\mu \mathrm{m} \mathrm{EC}$, (e) bulk $\mathrm{NH}_{4}^{+}$, and (f) super- $\mu \mathrm{m}$ OC associated with each of the source region flow patterns by season.

corresponding lowered frequency of warm season cold fronts that penetrate to the latitude of Bermuda.

The frequencies of days during which (1) near-surface flow was in sector, with wind speeds greater than $1 \mathrm{~m} \mathrm{~s}^{-1}$ and no precipitation, for greater than $10 \%$ of the day, (2) sam- ples were collected, and (3) the quality-assured data yielded values that were greater than analyte DLs were substantially less than $100 \%$ of all days. Therefore, as indicated previously, the number of days during which detectable values were measured varied among analytes and, consequently, the 

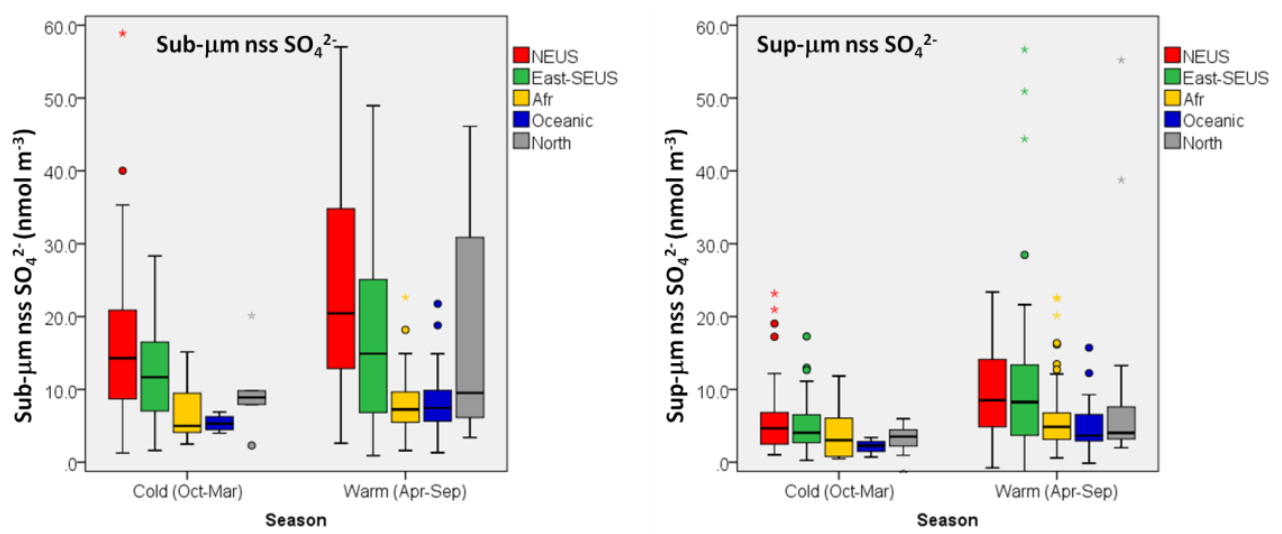

(a)

(b)
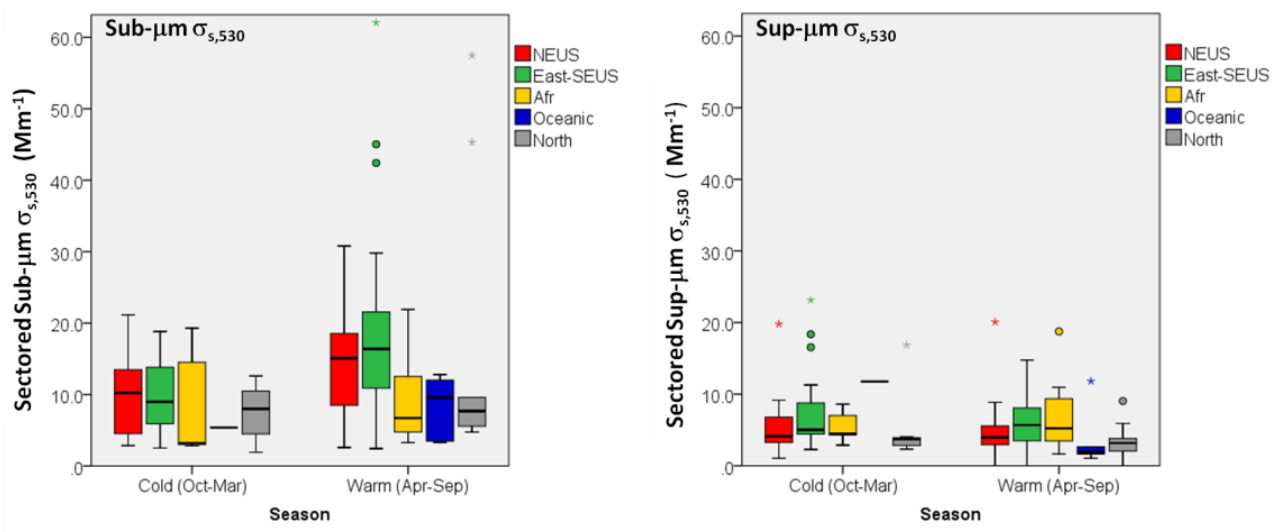

(c)

(d)
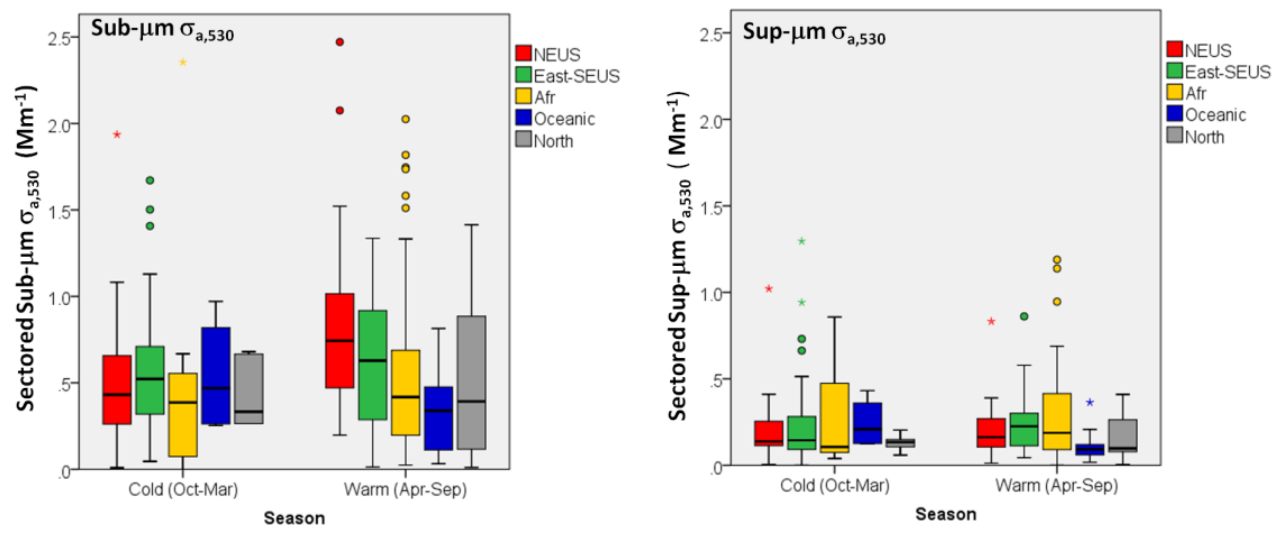

(e)

(f)

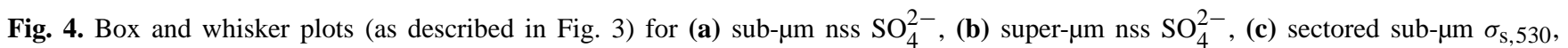
(d) sectored super- $\mu \mathrm{m} \sigma_{s, 530}$, (e) sectored sub- $\mu \mathrm{m} \sigma_{\mathrm{a}, 530}$, and (d) sectored super- $\mu \mathrm{m} \sigma_{\mathrm{a}, 530}$ associated with each of the source region flow patterns by season.

corresponding transport climatology for each analyte also varied. For example, bulk nss $\mathrm{SO}_{4}^{2-}$ data are available for $23 \%$ of all days during the cold season and $33 \%$ of all days during the warm season. Consequently, the transport frequencies for all days (Fig. 2a and b) differ somewhat from those corresponding to the subset of days for which data are 
available (Table 1). The frequencies for the subsets of all days during each season for which bulk nss $\mathrm{SO}_{4}^{2-}$ was characterized are depicted in Fig. 2c, d. This flow climatology is similar to those for analytes that were present in most samples at levels greater than DLs (Table 1). Near-surface winds that were out of the marine sampling sector were most frequent under conditions of post frontal flow from the NEUS or the North. Because these transport conditions occur more frequently in the cool season (Fig. 2a), the transport frequencies for bulk nss $\mathrm{SO}_{4}^{2-}$ from the NEUS (41\%) and North (4\%) during the cool season (Fig. 2c) are somewhat less than those for all days (Fig. 2a; $49 \%$ and $9 \%$, respectively). The corresponding differences during the warm season were relatively smaller (Fig. 2b, d).

\subsection{Aerosol characteristics by flow pattern}

The significance of differences in distributions of aerosol properties and meteorological conditions among the five flow patterns for each season are summarized in Table 2. Distributions of selected chemical and optical properties of aerosols associated with each flow regime during each season are depicted as box and whisker plots (10th, 25th, 50th, 75th, and 90th percentiles plus individual outlier points) in Figs. 3, 4, and 5. These results illustrate clear seasonal and flowdependent differences consistent with previous chemical climatologies for ozone (Moody et al., 1995) and the chemical composition of precipitation on Bermuda (Moody and Galloway, 1988). Variations in mean meteorological conditions by flow pattern are shown in Table 3 .

\subsubsection{Cool season}

The average temperature and relative humidity differed significantly among flow patterns with relatively warmer conditions associated with oceanic flow (transport under a Bermuda High) and relatively cooler conditions with transport from the North. Higher relative humidities were associated with oceanic transport and flow from Africa over the tropical and subtropical NAO whereas lower relative humidities were consistently associated with transport from the NEUS (Table 3), which was dominated by post-cold frontal conditions. Relative to other flow regimes, median concentrations of nss $\mathrm{SO}_{4}^{-2}, \mathrm{NO}_{3}^{-}, \mathrm{NH}_{4}^{+}$associated with bulk aerosol and $\mathrm{EC}$ associated with sub- $\mu \mathrm{m}$ aerosol were higher in flow with North American origin, whereas oceanic air contained relatively higher concentrations of $\mathrm{CH}_{3} \mathrm{SO}_{3}^{-}$(Fig. 3). Super- $\mu \mathrm{m}$ nss $\mathrm{Ca}^{2+}$ was relatively higher in transport from Africa (not shown) and correlated significantly with mineral aerosol mass. Despite differences in composition, corresponding differences in the aerosol scattering and absorption during this season were not significant at $95 \%$ confidence levels (Table 2). However, cool season flow was dominated by transport from North America and, consequently, relatively few samples were associated with other flow pat- terns thereby limiting statistical power in evaluating the significance in variability as a function of transport regime.

\subsubsection{Warm season}

During the warm season, flow from the NEUS was less frequent (Fig. 2) but, as in the cool season, it was associated with cooler and dryer conditions relative to other flow regimes. The warmest and wettest air masses arrived under the strong ridges of high pressure associated with African (AFR) transport. Absolute and relative variability in bulk nss $\mathrm{SO}_{4}^{-2}, \mathrm{NO}_{3}^{-}$, and $\mathrm{NH}_{4}^{+}$among flow regimes was greater during the warm season and the highest median concentrations were associated with NEUS and East-SEUS outflow from North America (Fig. 3). Relative to the cool season, $\mathrm{CH}_{3} \mathrm{SO}_{3}^{-}$concentrations were significantly higher overall during the warm season but did not vary significantly among flow regimes. Aerosol scattering and absorption varied significantly across transport regimes (Table 2), with the greatest absolute differences associated with the sub- $\mu \mathrm{m}$ size fraction (Fig. 4). Sub- $\mu$ m EC concentrations during the warm season were lower overall than those during the cool season and varied significantly among transport regimes (Table 2, Fig. 3d). The highest median values for sub- $\mu$ m EC, scattering and absorption at $530 \mathrm{~nm}$ were all associated with the NEUS and East-SEUS flow regimes. The higher median sub$\mu \mathrm{m}$ SSA associated with East-SEUS relative to NEUS flow indicates greater contributions of scattering to total extinction by sub- $\mu \mathrm{m}$ aerosols associated with that regime (Fig. 5). In contrast, transport from the NEUS and AFR delivered aerosols that exhibit relatively greater absorption (Fig. 4). In particular, extreme events with sub- $\mu \mathrm{m}$ absorption greater than $2 \mathrm{Mm}^{-1}$ and sub- $\mu \mathrm{m}$ SSA less than 0.9 were sampled under both of these flow patterns. However, the corresponding AAEs indicate that the spectral dependence of absorption by aerosol populations from the NEUS and AFR source regions differed (Fig. 5). Absorption by mineral aerosols associated primarily with African flow increases with decreasing wavelength resulting in a relatively greater AAEs, whereas absorption by combustion-derived aerosols associated primarily with the NEUS absorb more uniformly across the spectral range yielding AAEs closer to 1. The African (AFR) flow pattern also delivered relatively higher concentrations of nss $\mathrm{Ca}^{2+}$ and mineral aerosol concentrations (not shown) consistent with the transport of Saharan dust from northern Africa.

Based on median values, super- $\mu$ m OC was most concentrated in flow from the NEUS. However, the upper ends of the distributions for both the East-SEUS and North extended to relatively higher concentrations (Fig. 3f). Some of these higher concentrations were associated with identifiable biomass burning events in the eastern US and Canada. A specific example is discussed in more detail under case studies below. 


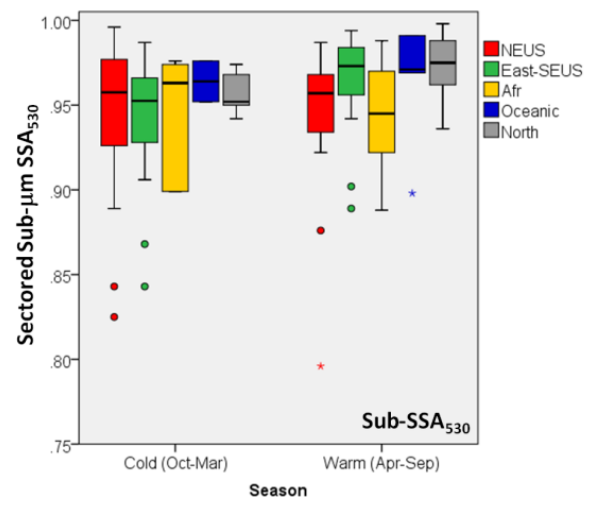

(a)

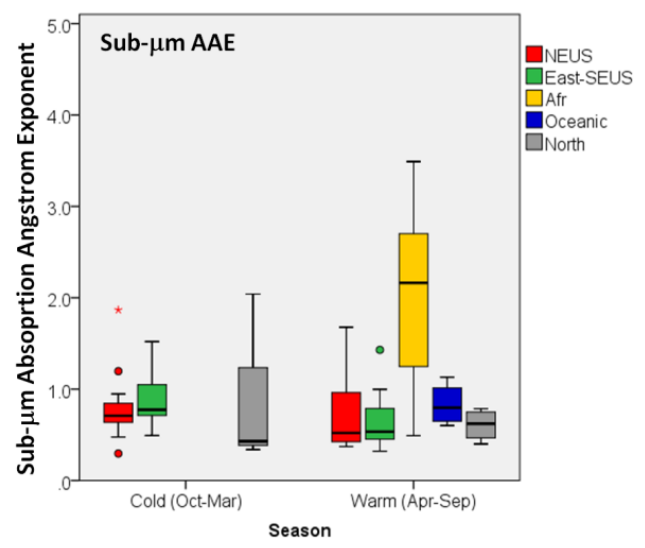

(c)

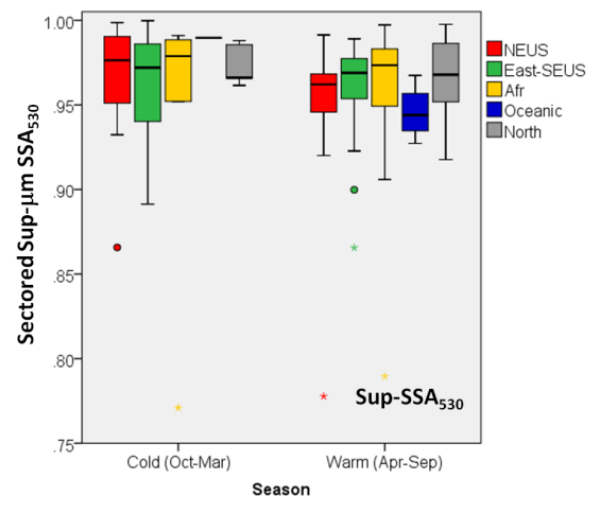

(b)

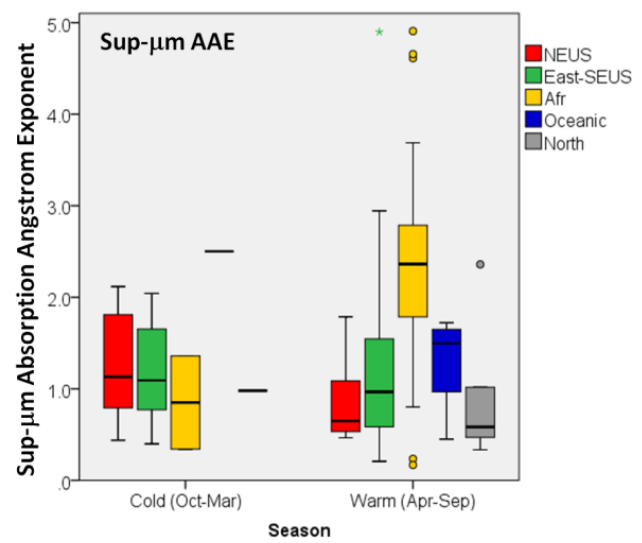

(d)

Fig. 5. Box and whisker plots (as described in Fig. 3) for (a) sub- $\mu \mathrm{m} \mathrm{SSA} \mathrm{S}_{530}$, (b) super- $\mu \mathrm{m} \mathrm{SSA}_{530}$, (c) sub- $\mu \mathrm{m}$ AAE, and (d) super- $\mu \mathrm{m}$ AAE associated with each of the source region flow patterns by season.

It is evident from the above that emissions over continental regions surrounding the North Atlantic basin significantly influenced the chemical and optical properties of air transported to Bermuda from those regions. In contrast, oceanic flow was associated with the lowest or near-lowest median values and the narrowest ranges in bulk nss $\mathrm{SO}_{4}^{2-}, \mathrm{NO}_{3}^{-}$, $\mathrm{NH}_{4}^{+}$, super- $\mu \mathrm{m} \mathrm{OC}$, and absorption (Figs. 3, 4). These relationships suggest that the chemical and optical characteristic of aerosols associated with the oceanic flow regime can serve as regional backgrounds for the western North Atlantic Ocean against which the contributions of continental influences can be evaluated. We recognize that the oceanic flow regime is influenced to some extent by emissions over surrounding continents and, consequently, the associated aerosol characteristics are viewed as upper limits for actual background conditions.

\subsection{Correlations and scattering efficiency}

Influences of chemical composition on the corresponding optical properties of aerosols over the western NAO were evalu- ated as a function of transport regime using bivariate correlations based on linear least-squares regressions. Considering all data together, sectored bulk scattering at $530 \mathrm{~nm}$ during the warm season was significantly correlated with the paired bulk nss $\mathrm{SO}_{4}^{2-}$ concentration $(r=0.84, n=81)$, indicating that overall, $71 \%$ of the variability in total scattering can be explained by variability in bulk nss $\mathrm{SO}_{4}^{2-}$. However, the corresponding slopes for paired data associated with individual flow regimes differed significantly (Fig. 6). Table 4 includes the regression results for events characterized as transport from the NEUS, transport from AFR, transport associated with three outliers (identified as the yellow crosses in Fig. 6), and transport from AFR including the three outliers. The three outliers correspond to individual events that were transported from the NEUS but contained high concentrations of mineral aerosol. Based on their composition and radiative characteristics, these events were similar to dust events associated with transport from Africa. They are discussed in more detail in Sect. 3.7. Regression lines for the NEUS ( $r=0.91$, $n=18)$ and AFR+outliers ( $r=0.79, n=27)$ flow patterns exhibit the greatest divergence and bracket most of the paired 


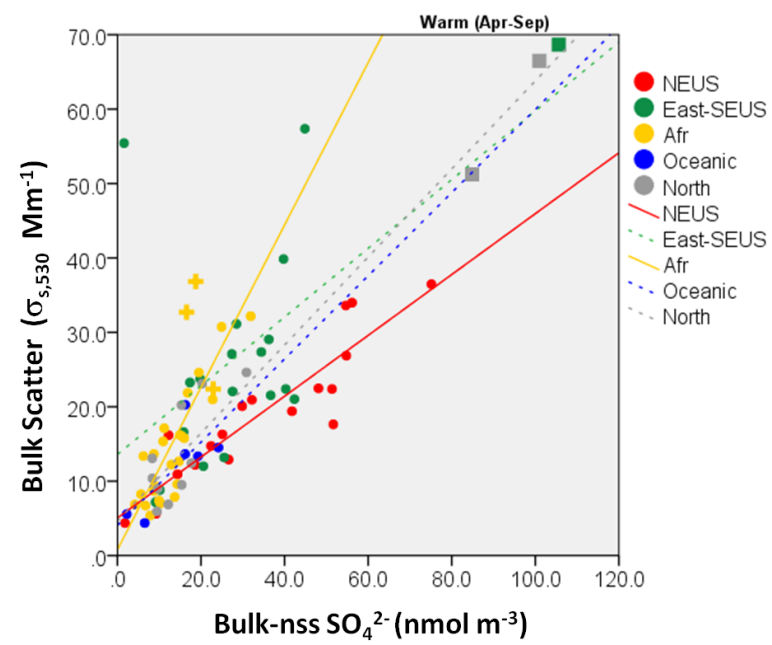

Fig. 6. Sectored bulk $\sigma_{\mathrm{s}, 530}$ versus bulk nss $\mathrm{SO}_{4}^{2-}$ associated with each of the source region flow patterns during the warm season; color-coded lines depict the corresponding regressions. Regression statistic for the solid lines (NEUS and AFR+outliers) are reported in Table 4.

data associated with the other flow regimes. Several other outliers (identified with squares) are also discussed in more detail in Sect. 3.7.

Aerosol components other than nss $\mathrm{SO}_{4}^{2-}$ (including other nss ionic constituents, primary marine aerosol, crustal dust, and organic matter) also scatter incident solar radiation (e.g., Quinn and Bates, 2005; Li et al., 2006). Super- $\mu$ m-diameter aerosol at Bermuda is composed primarily of inorganic seasalt species (Table 1) and associated water, which dominate scattering by that size fraction. Because virtually all $\mathrm{NO}_{3}^{-}$, which originates from secondary sources, is also associated with the super- $\mu \mathrm{m}$ size fraction (Table 1 ); $\mathrm{NO}_{3}^{-}$has relatively minor influences on scattering. Scattering efficiencies are conventionally apportioned among the major aerosol components or calculated relative to total aerosol mass and reported in units of $\mathrm{m}^{2} \mathrm{gm}^{-1}$. As discussed previously, many individual measurements of mineral aerosol and OC were less than DLs and, consequently, their associated contributions to scattering cannot be apportioned directly. However, the significant correlations evident in Fig. 6 (molar units) and Table 4 (same data in mass units) indicate that the relative mixture of most light-scattering aerosol components within each transport regime co-varied with nss $\mathrm{SO}_{4}^{2-}$. Consequently, we adopted nss $\mathrm{SO}_{4}^{2-}$ as a reasonable proxy and useful predictive tool for all scattering aerosol components within each flow regime and have defined a modified mass scattering efficiency (mMSE) as the slope for the regression of scattering at $530 \mathrm{~nm}$ versus nss $\mathrm{SO}_{4}^{2-}$ mass. The lower limit for individual measurements of scattering coefficients associated with all transport regimes (about $5 \mathrm{Mm}^{-1}$, Fig. 6) represents background scattering by particles such as mechanically produced marine aerosols that are uncorrelated with nss $\mathrm{SO}_{4}^{2-}$.
These modified mass scattering efficiencies (mMSE) based on bulk scattering (bulk- $\sigma_{\mathrm{s}, 530}$ ) versus bulk nss $\mathrm{SO}_{4}^{2-}$ mass for the AFR and NEUS flow regimes (11.4 vs. $4.3 \mathrm{~m}^{2} \mathrm{gm}^{-1}$ ) differ by a factor of 2.7 and the corresponding correlation coefficients indicate that these relationships account for greater than $91 \%$ and $63 \%$, respectively, of the associated variability in light scattering (Table 4). This greater scattering per unit mass of sulfate in AFR flow represents implicit contributions from other associated aerosol components including mineral dust and organic carbon that are transported with the nss $\mathrm{SO}_{4}^{2-}$. The fine fraction of scattering also differs between these regimes. Based on median values, sub- $\mu \mathrm{m}$ aerosol nss $\mathrm{SO}_{4}^{2-}$ accounts for $71 \%$ of total scattering in NEUS flow but only $34 \%$ in AFR flow. These differences are driven in part by the larger mass median diameter of mineral aerosol at Bermuda (2.0 to $2.4 \mu \mathrm{m}$; Arimoto et al., 1997) relative to pollutant aerosol from North America (less than $1 \mu \mathrm{m})$.

Considering only scattering associated with the sub- $\mu \mathrm{m}$ size fraction, the mMSE for AFR+outliers is a factor of two greater than that for NEUS flow (9.5 versus $4.7 \mathrm{~m}^{2} \mathrm{gm}^{-1}$ ), again, indicative of the combined influences of sub- $\mu \mathrm{m}$ nss $\mathrm{SO}_{4}^{2-}$ and associated scattering aerosol components. However, the lower correlation coefficients indicate that these relationships for sub- $\mu \mathrm{m}$ aerosol explain less of the observed variability in light scattering for NEUS flow and AFR flow relative to those for bulk aerosol (Table 4).

Previous studies that characterized all of the aerosol mass components found that median MSE at $550 \mathrm{~nm}$ and $55 \%$ $\mathrm{RH}$ based on the total mass of all sub- $\mu \mathrm{m}$ aerosol ranged from $2.97 \mathrm{~m}^{2} \mathrm{gm}^{-1}$ for continental air containing pollutants and dust during ACE-Asia to $4.73 \mathrm{~m}^{2} \mathrm{gm}^{-1}$ in air that had been over the ocean for greater than 5 days during the INDOEX campaign (see Table 6, Bates et al., 2006). MSE at $550 \mathrm{~nm}$ and $55 \% \mathrm{RH}$ based on total sub- $\mu \mathrm{m}$ mass over the WNAO during the ICARTT campaign ranged from 2.5 to $5.0 \mathrm{~m}^{2} \mathrm{gm}^{-1}$, and at lower wavelengths from 3.0 to $7.0 \mathrm{~m}^{2} \mathrm{gm}^{-1}$ (Bates et al., 2006). Li et al., (1996) employed a MSE for nss $\mathrm{SO}_{4}^{-2}$ over the North Atlantic of $2.8 \mathrm{~m}^{2} \mathrm{~g}^{-1}$, based on observations near the Azores (Hegg et al., 1994), a location that is generally influenced to a lesser degree by dust and North American emissions than Bermuda. The mMSEs calculated in this paper using only nss $\mathrm{SO}_{4}^{2-}$ mass and dry aerosol are not directly comparable quantitatively with those based on total mass at $55 \% \mathrm{RH}$ as reported by Bates et al. (2006). However, the data do suggest a consistent picture of relatively greater scattering in marine air influenced by mineral aerosol relative to polluted continental emissions. The higher mMSE relative to nss $\mathrm{SO}_{4}^{2-}$ in African flow compared to NEUS flow reflects contributions to scattering by mineral aerosol. The three outliers, representing dust events associated with transport from the NEUS, are consistent with this interpretation, and will be discussed further in Sect. 3.7. 
Table 4. Linear regression analyzes of $\sigma_{\mathrm{s}, 530}\left(\mathrm{Mm}^{-1}\right)$ against nss $\mathrm{SO}_{4}^{2-}\left(\mu \mathrm{g} \mathrm{m}^{-3}\right)$, slopes are in units of $\mathrm{m}^{2} \mathrm{gm}^{-1}$.

\begin{tabular}{|c|c|c|c|c|c|c|c|c|c|}
\hline Model $^{1}$ & $\begin{array}{l}\text { Correlation } \\
\text { coefficient }\end{array}$ & Intercept & $(\text { S.E. })^{2}$ & Sig. ${ }^{3}$ & Slope & $(\text { S.E. })^{2}$ & Sig. ${ }^{3}$ & $\begin{array}{c}\text { Explained } \\
\text { variance }(\%)\end{array}$ & $n$ \\
\hline \multicolumn{10}{|c|}{ 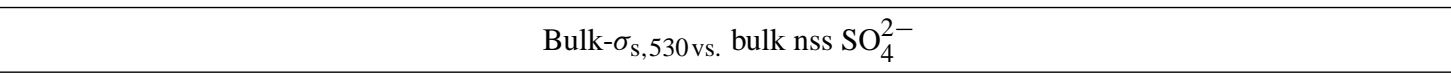 } \\
\hline NEUS & 0.91 & 5.1 & 1.9 & 0.017 & 4.3 & 0.49 & 0.000 & 82 & 18 \\
\hline AFR & 0.88 & 1.0 & 1.7 & 0.552 & 10.3 & 1.2 & 0.000 & 77 & 24 \\
\hline OUTLIERS & 0.95 & $0.0^{4}$ & $*$ & $*$ & 15.8 & 3.6 & 0.049 & 90 & 3 \\
\hline AFR + OUTLIERS & 0.79 & 0.80 & 2.6 & 0.757 & 11.4 & 1.7 & 0.000 & 63 & 27 \\
\hline \multicolumn{10}{|c|}{ Sub- $\sigma_{\mathrm{s}, 530 \text { vs. }}$ sub-nss $\mathrm{SO}_{4}^{2-}$} \\
\hline NEUS & 0.84 & 3.7 & 2.1 & 0.105 & 4.7 & 0.74 & 0.000 & 71 & 18 \\
\hline AFR & 0.60 & 0.1 & 2.5 & 0.969 & 12.6 & 3.6 & 0.002 & 36 & 24 \\
\hline OUTLIERS & 0.94 & $*^{4}$ & $*^{4}$ & $*^{4}$ & 10.2 & 2.7 & 0.064 & 87 & 3 \\
\hline AFR+OUTLIERS & 0.58 & 2.1 & 2.1 & 0.322 & 9.5 & 2.7 & 0.001 & 34 & 27 \\
\hline
\end{tabular}

1 Analyzes are reported by transport pattern for NEUS flow and AFR flow. Three events identified as NEUS dust events have been designated OUTLIERS and are reported separately, and are also grouped with the other "dust" events in flow from AFR, and plotted as (+) in Fig. 6 .

2 Standard Error of the estimate (regression intercept or slope).

${ }^{3}$ Significance level of $t$ test.

${ }^{4}$ Regression of outliers forced through 0.

Table 5. Mean nss $\mathrm{SO}_{4}^{-2}$ and $\mathrm{CH}_{3} \mathrm{SO}_{3}^{-}$concentrations for Bermuda data from 1989 to 1990 (Savoie et al., 2002) and current Bermuda data from 2006 to 2009, with estimates of the the percentage contribution of anthropogenic (and \% error), based on the derived $\mathrm{nssSO}_{4}^{-2} / \mathrm{CH}_{3} \mathrm{SO}_{3}^{-}$ratio of 18.8 ( \pm 2.2 ) (Savoie et al., 2002).

\begin{tabular}{|c|c|c|c|c|}
\hline Data set & $\begin{array}{l}\text { Tot nssSO }{ }_{4}^{-2} \\
\text { mean }\left(\mu \mathrm{g} \mathrm{m}^{-3}\right)\end{array}$ & $\begin{array}{l}\mathrm{CH}_{3} \mathrm{SO}_{3}^{-} \\
\text {mean }\left(\mu \mathrm{g} \mathrm{m}^{-3}\right)\end{array}$ & $\begin{array}{l}\text { Anthropogenic nss } \\
\mathrm{SO}_{4}^{2-}(\%)\end{array}$ & Error (\%) \\
\hline Savoie ' $89-90^{1}$ & 2.35 & 0.378 & 70 & 3.5 \\
\hline '90-91* & 2.34 & 0.353 & 72 & 3.3 \\
\hline Total & 2.34 & 0.366 & 71 & 3.4 \\
\hline Moody '06-07' ${ }^{1}$ & 2.29 & 0.488 & 60 & 4.7 \\
\hline '07-08 & 1.83 & 0.515 & 50 & 6.2 \\
\hline '08-09 ${ }^{1}$ & 1.67 & 0.332 & 62 & 4.4 \\
\hline Total & 1.95 & 0.455 & 561 & 5.1 \\
\hline \multicolumn{5}{|c|}{ Moody '06-09 by flow pattern } \\
\hline NEUS & 2.54 & 0.332 & 75 & 2.9 \\
\hline East-SEUS & 2.12 & 0.444 & 61 & 4.6 \\
\hline AFR & 1.29 & 0.514 & 25 & 8.8 \\
\hline Oceanic & 1.20 & 0.654 & -2 & 12. \\
\hline North & 2.37 & 0.491 & 61 & 4.6 \\
\hline \multicolumn{5}{|l|}{ Moody '06-09 } \\
\hline \multicolumn{5}{|l|}{ By Season } \\
\hline Cool (Oct-Mar) & 1.72 & 0.258 & 72 & 3.4 \\
\hline Warm (Apr-Sep) & 2.13 & 0.602 & 47 & 6.2 \\
\hline
\end{tabular}

* annual periods defined July-June.

\subsection{Anthropogenic versus Biogenic nss $\mathrm{SO}_{4}^{-2}$}

Based on a detailed evaluation of ionic and elemental tracers associated with aerosols measured at Bermuda from 1989 to 1991, Savoie et al. (2002) derived a mass ratio of $18.8 \pm 2.2$ for the ratio of nss $\mathrm{SO}_{4}^{2-}$ to $\mathrm{CH}_{3} \mathrm{SO}_{3}^{-}$produced from the at- mospheric oxidation of biogenic $\left(\mathrm{CH}_{3}\right)_{2} \mathrm{~S}$ emitted from the ocean surface. This ratio did not vary seasonally and was statistically indistinguishable with comparable ratios derived independently for the tropical NAO at Barbados (19.6 \pm 2.1$)$ and measured in the remote tropical South Pacific Ocean at American Samoa $(18.1 \pm 0.9)$. Using the ratio derived for 
Bermuda, relative contributions of $\mathrm{nss} \mathrm{SO}_{4}^{2-}$ from anthropogenic versus marine biogenic sources in the current data set were differentiated and compared with results reported by Savoie et al. (2002). The reported uncertainties correspond to those for the $\mathrm{SO}_{4}^{2-} / \mathrm{CH}_{3} \mathrm{SO}_{3}^{-}$ratio reported by Savoie et al. (2002) and do not reflect propagation of errors associated with the measured total nss $\mathrm{SO}_{4}^{2-}$ and $\mathrm{CH}_{3} \mathrm{SO}_{3}^{-}$in this data set. Consequently, the reported uncertainties represent lower limits.

Based on average values, total nss $\mathrm{SO}_{4}^{2-}$ concentrations decreased by $17 \%$ between the earlier measurement period (1989 to 1991) reported by Savoie et al. (2002) and that evaluated herein (2006 to 2009) (Table 5). These decreases were driven in part by large reductions in $\mathrm{SO}_{2}$ emissions over United States as mandated by the Clean Air Act. Between 1988 and 2009, $\mathrm{SO}_{2}$ emissions decreased by $64 \%$ (http: //www.epa.gov/ttn/chief/trends/) resulting in decreased production of particulate $\mathrm{SO}_{4}^{2-}$ (http://www.epa.gov/airtrends) and consequently reduced export of pollutant $S$ over the western North Atlantic Ocean. Similarly, recent analyzes of fine particle mass and EC from national parks and other remote locations show a $25 \%$ decrease between 1990 and 2004 (Murphy et al., 2011). A more comprehensive comparison of long-term trends in aerosol and precipitation composition at Bermuda are reported by a companion manuscript by Keene et al. (2014) which is currently in preparation.

Although the average $\mathrm{CH}_{3} \mathrm{SO}_{3}^{-}$concentration for the entire period of record from 2006 to 2009 was higher than that for 1989-1991, the ranges for annual averages overlapped (Table 5). Relative to 1989-1991, anthropogenic contributions during 2006 to 2009 were proportionately smaller (by $15 \%$ ) and marine biogenic contributions proportionately larger (Table 5). These data were also stratified by transport pattern and by season. The results indicate that during the more recent period of observations, flow from NEUS was associated with much greater anthropogenic contributions $(75 \%)$ relative to the transport from Africa $(25 \%)$. Anthropogenic contributions to mean nss $\mathrm{SO}_{4}^{2-}$ concentrations associated with oceanic flow were variable, note the percent error in Table 5, but statistically indistinguishable from $0.0 \%$. These results imply that events classified as oceanic flow represent a reasonable background for anthropogenic particulate nss $\mathrm{SO}_{4}^{2-}$ over the western NAO. Relative to the warm season, the higher frequency of transport from North America to Bermuda during the cool season coupled with the lower nss $\mathrm{SO}_{4}^{2-}$ from biogenic sources is evident in the greater fractional contribution of anthropogenic nss $\mathrm{SO}_{4}^{2-}$ from October to March (Table 5).

\subsection{Case studies for events associated with different transport regimes}

More detailed evaluations of specific cases yield additional insight regarding the chemical and optical properties of aerosols over the western North Atlantic Ocean as a function of transport region and the correspondence between surface observations and regional satellite total column measures of AOD and extinction Ångström exponent (EAE). For example, the highest mineral aerosol concentrations observed on Bermuda during the current study occurred in association with a large dust outbreak transported from Africa between 28 July and 3 August, 2006. Figure 1c depicts one of the FLEXPART retroplumes (31 July to 1 August) during this period. During the first day of the event, satellite observations by MODIS revealed a high regional $\mathrm{AOD}_{550}$ of 0.62 and an EAE of 0.354 , indicative of an aerosol number size distribution dominated by super- $\mu \mathrm{m}$ diameter particles. Mineral aerosol mass measured at the THAO was $45.6 \mu \mathrm{g} \mathrm{m}^{-3}$ with the majority $(57 \%)$ associated with the super- $\mu \mathrm{m}$ size fraction. These dusty conditions persisted for several days; on 1 August, the MODIS AOD 550 was 0.40, the EAE was 0.44, and the dust concentrations at THAO increased to a maximum of $71.0 \mu \mathrm{g} \mathrm{m}^{-3}$, with $61 \%$ in the super- $\mu \mathrm{m}$ size fraction. Unfortunately, scattering data are not available for this period. However, the event was associated with high absorption by bulk aerosol $\left(\sigma_{\mathrm{a} 530}\right)$ ranging from 2.4 to $2.7 \mathrm{Mm}^{-1}$ between 28 July and 1 August. Absorption also varied significantly with wavelength, yielding AAEs ranging from 2.56 to 2.72 , which are consistent with the wavelength dependence of absorption by dust. Sub- $\mu$ m aerosols accounted for $75 \%$ and $65 \%$ of absorption on 28-29 July and 1-2 August, respectively. The relatively high $\mathrm{CH}_{3} \mathrm{SO}_{3}^{-}$concentrations associated with bulk aerosol on 28-29 July and 1-2 August (1.12 and 0.88 , respectively) coupled with the ratio of biogenic $\mathrm{SO}_{4}^{2-}$ to $\mathrm{CH}_{3} \mathrm{SO}_{3}^{-}$reported by Savoie et al. (2002) suggests that approximately $74 \%$ and $47 \%$, respectively, of the associated nss $\mathrm{SO}_{4}^{2-}$ originated from $\left(\mathrm{CH}_{3}\right)_{2} \mathrm{~S}$ oxidation. This also demonstrates the anthropogenic contribution to nss $\mathrm{SO}_{4}^{2-}$ increased during this period as the transport shifted from mostly African influenced air to transport that had a greater contribution from the eastern United States. The relationships between bulk absorption versus bulk nss $\mathrm{SO}_{4}^{2-}$ on these days are depicted with yellow asterisks in Fig. 7. Again, the significant difference in slopes illustrate that there is more absorption per unit sulfate in AFR flow relative to the NEUS, consistent with the observation that these events have a high mineral aerosol contribution.

Next we illustrate a three-day event from 18 to 20 June 2007 that was associated with high absorption and scattering coupled with flow that transitioned from the North to the East-SEUS. MODIS imagery on 19 June showed a large plume of smoke and haze near Bermuda (Fig. 8) that had been pushed out from eastern North America with a frontal passage. MODIS imagery also revealed relatively high regional $\mathrm{AOD}_{550}$ (daily averages of $0.19,0.37$, and 0.31 ) and high EAEs (daily averages of 1.2, 1.1, and 1.4 at $550 \mathrm{~nm}$ ) indicating that sub- $\mu \mathrm{m}$ diameter particles dominated column extinction. The relatively high bulk $\sigma_{\mathrm{a} 530}(1.74,1.36$, and 1.15$)$ measured at THAO did not vary significantly with wavelength yielding AAEs less than 


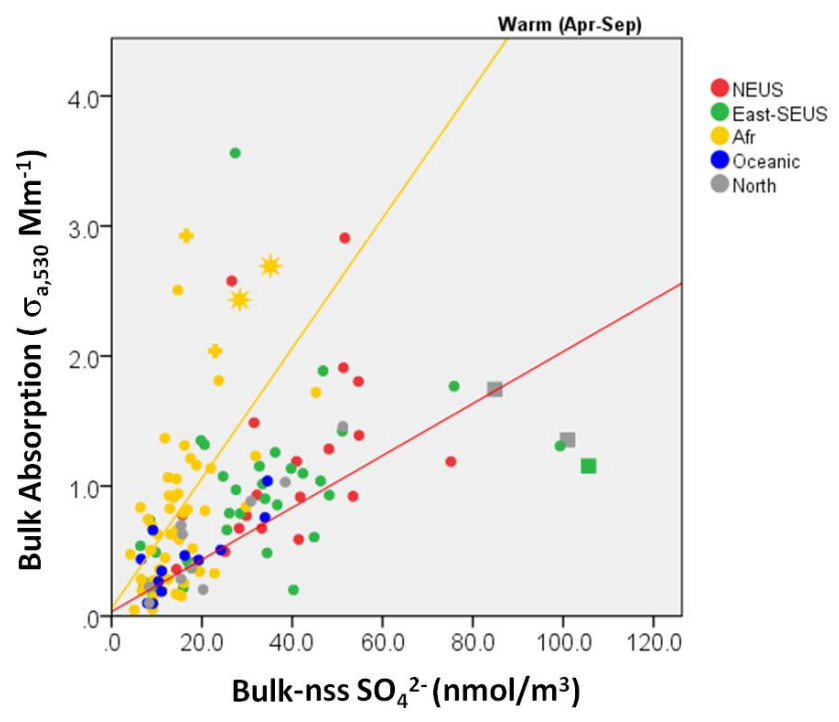

Fig. 7. Sectored bulk $\sigma_{\mathrm{a}, 530}$ versus bulk nss $\mathrm{SO}_{4}^{2-}$ concentration associated with each of the source region flow patterns during the warm season, with specific events highlighted: asterisks mark the African dust event from 28 June and 1 August 2006; crosses mark the dust event from 21 and 23 April 2009; squares mark the polluted haze/biomass burning event from North and East-SEUS, 18, 19 and 20 June 2007. Regression lines are plotted for NEUS, $r=0.49$ with intercept of 0.03 and slope of 0.02 , and for AFR, $r=0.56$ with intercept of 0.06 and slope of 0.05 .

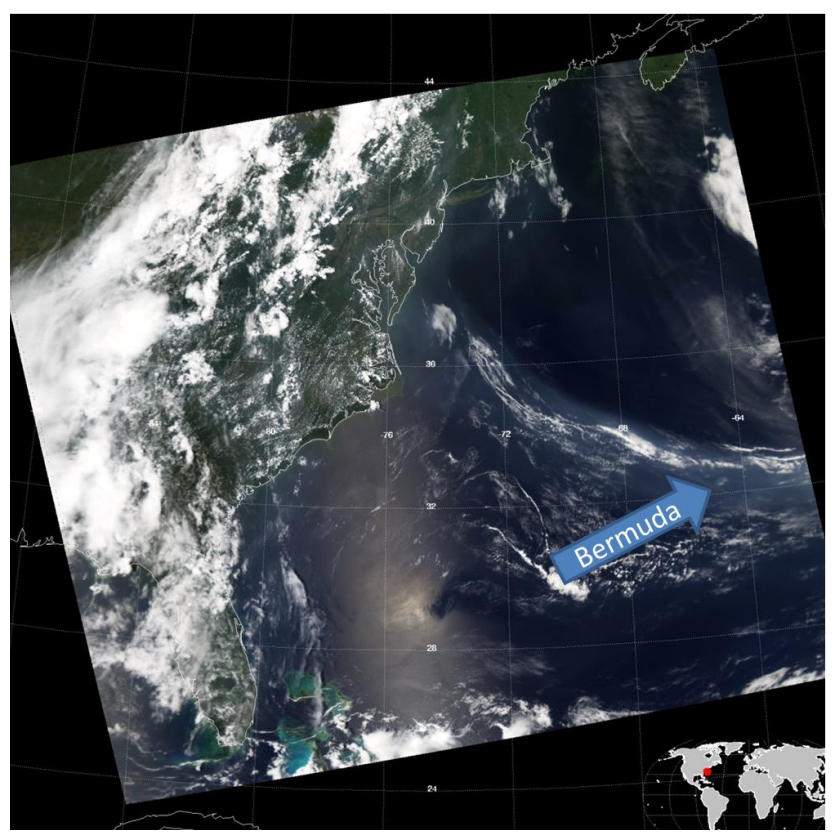

Fig. 8. MODIS Aqua true color image from 19 June 2007, midpoint of the three day polluted haze/biomass burning event with high scattering, absorption, nss $\mathrm{SO}_{4}^{2-}$, OC, and EC transported from North and East-SEUS on 18, 19 and 20 June 2007 as a frontal boundary advanced toward Bermuda from the north.
1.0 suggesting absorption dominated by combustion-derived aerosols. Concentrations of elemental and organic carbon shifted over the three days from only super- $\mu$ m observations above DLs on June 18 ( $32.3 \mathrm{OC}$ and $8.1 \mathrm{EC} \mathrm{nmol} \mathrm{C} \mathrm{m}^{-3}$ ), to those associated with the sub- $\mu \mathrm{m}$ size fraction above DLs on June 20 (109.5 OC and 6.1 EC, $\left.\mathrm{nmol} \mathrm{C} \mathrm{m}{ }^{-3}\right)$. Sub- $\mu \mathrm{m}$ nss $\mathrm{K}^{+}$concentrations were close to the warm season average throughout the event (ranging from 0.58 to $0.62 \mathrm{nmol} \mathrm{m}^{-3}$ ) and bulk nss $\mathrm{SO}_{4}^{2-}$ was present at high concentrations (ranging from 84.9 to $105.6 \mathrm{nmol} \mathrm{m}^{-3}$ ). The sub- $\mu \mathrm{m}$ size fraction accounted for $86 \%$ to $90 \%$ of bulk scattering (51.2 to $58.7 \mathrm{Mm}^{-1}$ ) during the period. Absorption coefficients were also dominated $(70 \%$ to $80 \%$ ) by the sub- $\mu \mathrm{m}$ size fraction. The relationships between bulk scattering $\left(\sigma_{\mathrm{s} 530}\right.$, Fig. 6$)$ and bulk absorption $\left(\sigma_{\mathrm{a} 530}\right.$, Fig. 7) versus bulk nss $\mathrm{SO}_{4}^{2-}$ for this event are depicted in the figures with squares. Smoke and haze visible in the MODIS image (Fig. 8) coupled with transport from the eastern US and the associated high nss $\mathrm{SO}_{4}^{2-}$ concentrations suggests that the chemical and optical properties of air during this period represent a mixture of aerosols from both biomass burning and fossil-fuel combustion.

During spring 2009, we characterized three events associated with NEUS flow that were distinct outliers in the plot of scattering versus nss $\mathrm{SO}_{2}^{-4}$ (Fig. 6, yellow crosses) and Table 4. The presence of detectable mineral aerosol mass and the relatively large contributions of super- $\mu \mathrm{m}$ aerosol

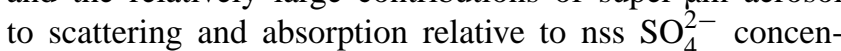
trations are more typical of dust laden air transported from Africa (such as the event described above) than NEUS pollution events. For example, on 21 April 2009 transport from the NEUS (depicted in Fig. 1a) the mineral aerosol concentration was $54.4 \mu \mathrm{g} \mathrm{m}^{-3}$. Half of the mineral aerosol mass was associated with the super- $\mu \mathrm{m}$ size fraction and, relative to other NEUS events, much more of the scattering and absorption was driven by the super- $\mu \mathrm{m}$ size fraction. All three events were associated with elevated column $\mathrm{AOD}_{550}(0.582$, 0.311 , and 0.222$)$, and satellite EAEs that were small (0.43, 0.56 , and 0.70), indicative of large particles. Visual inspection of the filters for 21 April indicated a yellowish-tan hue to the aerosol deposit, which was distinct from the more reddish hue filter typically associated with mineral dust of African origin. These events had moderate nss $\mathrm{SO}_{4}^{2-}$ concentrations and proportionately greater amounts were associated with super- $\mu \mathrm{m}$ particles (average of $69 \%$ ) relative to other NEUS flow. These three events are also identified in Fig. 7 with the yellow crosses, and based on their absorption characteristics, two of the days were similar to the absorption characteristics of the major dust event (Fig. 7, asterisk) from the summer of 2006, discussed above. Polluted Asian dust can contribute significantly to North American background air during spring (Koch et al., 2007; Yu et al., 2012). In addition, simulations with the NAAPS model output archive, available from the Naval Research Laboratory Aerosol website (http://www.nrlmry.navy.mil/aerosol/) 


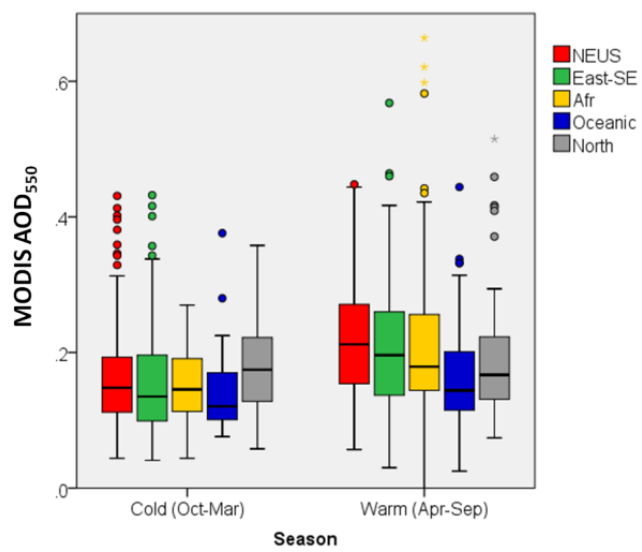

(a)

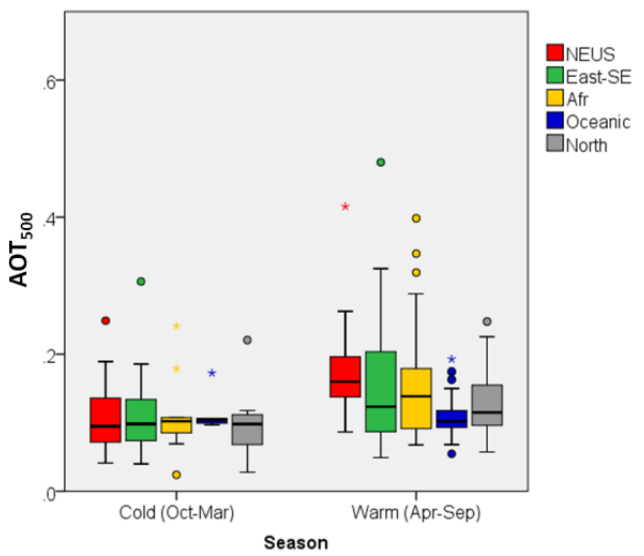

(b)

Fig. 9. Box and whisker plots (as described in Fig. 3) for (a) regional AOD measured by MODIS (Terra, at $550 \mathrm{~nm}$ ) on all days from 2006 to 2009; and (b) AERONET AOT (500 nm) from Bermuda January 2008 to June 2009 associated with each of the source region flow patterns by season.

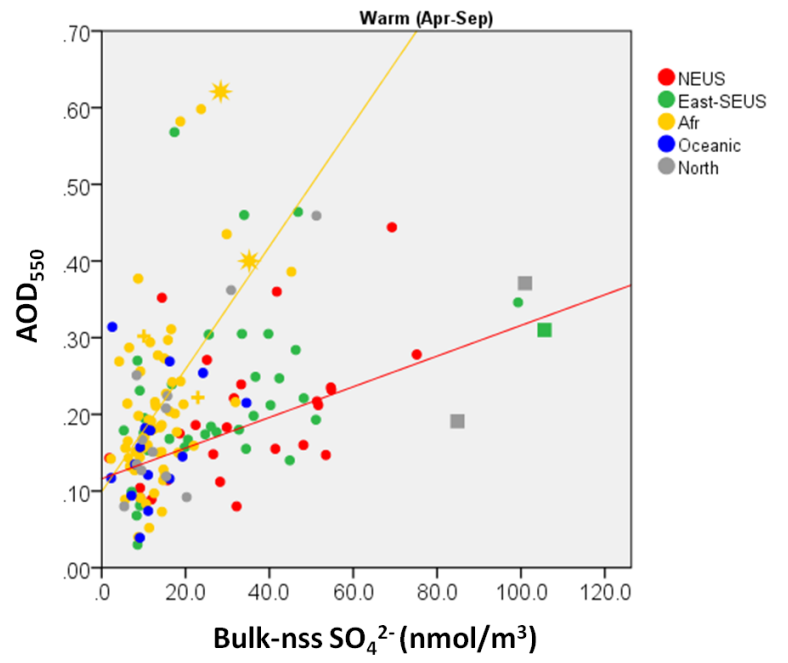

Fig. 10. MODIS regional aerosol optical depth (AOD, $550 \mathrm{~nm})$ versus bulk nss $\mathrm{SO}_{4}^{2-}$ concentration by flow patterns during the warm season months of April to September; symbols are as defined in Fig. 7. Regression lines for NEUS, $r=0.51$ with an intercept of 0.12 and a slope of 0.002 , and for AFR, $r=0.53$ with an intercept of 0.10 and slope of 0.008 .

suggest the presence of significant Asian dust over eastern North America during this period. Based on the above, we hypothesize that these unusual events represent a mixture of polluted dust of Asian origin with polluted air from the NEUS resulting in significant scattering and absorption, relatively low SSAs of 0.92 (bulk) and 0.89 (sub- $\mu \mathrm{m}$ ), and higher than average $\mathrm{NH}_{4}^{+}$.

The transport and aerosol characteristic associated with the events discussed above reveal contributions from multiple sources that often preclude simple definitive designations of source type for individual events. Nevertheless, viewed in aggregate, it is evident that physiochemical characteristics of aerosols (e.g., scattering versus nss $\mathrm{SO}_{4}^{2-}$ and absorption versus nss $\mathrm{SO}_{4}^{2-}$ ), diverge systematically between broadly different source regions.

\subsection{Aerosol optical depth}

Median values and distributions of satellite derived $\mathrm{AOD}_{550}$ from MODIS observations that correspond to the NEUS and AFR transport regimes differ significantly from the relatively lower values associated with the oceanic regime during the warm season (Fig. 9a). Similar relationships are evident in the smaller data set of $\mathrm{AOT}_{500}$ measured over Bermuda by AERONET between December 2007 to June of 2009 (Fig. 9b). AOT values are systematically lower than AOD by about 0.02 to 0.06 , consistent with previously reported comparisons (Smirnov et al., 2006). These differences result from several factors including the fact that satellite AOD measures backscattered radiance whereas AOT is primarily measuring forward scattered radiance. While there are no significant differences in the medians or distributions of AOD in NEUS versus AFR flow, there are differences in the MODIS EAE that reflect overall differences in the size distribution of the aerosol (EAE $=0.86$ for NEUS and $\mathrm{EAE}=0.74$ for $\mathrm{AFR}$ ).

Previously it was shown that bulk nss $\mathrm{SO}_{4}^{2-}$ correlates significantly with bulk scattering. One might expect paired nearsurface observations of aerosol scattering and aerosol composition to be correlated. However, results depicted in Fig. 10 reveal a statistically significant correspondence between total column extinction measured from space and corresponding concentrations of bulk nss $\mathrm{SO}_{4}^{2-}$ measured near the surface; and again, there are apparent differences in the relationships for NEUS versus AFR. These results are consistent with a paper by Aryal et al. (2013) based on a subset of the 
Table 6. Estimates of the change in radiative forcing associated with changes in the median aerosol optical depth (AOD) in transport from North America (NEUS) and North Africa (AFR) over Bermuda relative to the oceanic background.

\begin{tabular}{llll}
\hline $\begin{array}{l}\text { Transport } \\
\text { region }\end{array}$ & $\begin{array}{l}\Delta \text { median } \\
\text { MODIS AOD }(\delta)^{1}\end{array}$ & $\begin{array}{l}\text { Range of radiative } \\
\text { efficiency }{ }^{2}\left(\mathrm{~W} \mathrm{~m}^{-2} \delta^{-1}\right)\end{array}$ & $\begin{array}{l}\text { Median (range) of radiative } \\
\text { forcing }\left(\mathrm{W} \mathrm{m}^{-2}\right)^{3}\end{array}$ \\
\hline NEUS & 0.037 & -27 to -60 & $-1.6(-1.0$ to -2.2$)$ \\
AFR & 0.056 & -35 to -55 & $-2.5(-2.0$ to -3.1$)$ \\
\hline
\end{tabular}

1 Median AOD for continental source region minus Median AOD for oceanic source region, this data set.

${ }^{2}$ From Table 2, Anderson et al. (2005), based on regional aerosols over the ocean, Christopher and Zhang (2002), the lower range of efficiency for the NEUS comes from using the Global Ocean estimate of $-27 \mathrm{~W} \mathrm{~m}^{-2} \delta^{-1}$ derived from the GOCART model (Yu et al., 2004).

3 TOA clear-sky $24 \mathrm{~h}$ averaged effect on solar radiative flux calculated from median values of change in AOD and reported range in radiative efficiency.

Bermuda data reported here. Using data from 2009 in parallel with micro-pulse lidar vertical distributions of aerosol backscatter, Aryal et al. (2013) found aerosol optical properties measured near the surface were often significantly correlated with those averaged over the column.

These AOD data coupled with published satellite derived estimates for the radiative efficiency of aerosols per unit optical depth in North African $\left(-35\right.$ to $-55 \mathrm{~W} \mathrm{~m}^{-2} \delta^{-1}$ ) and North American outflow over the ocean $(-27$ to $-60 \mathrm{~W} \mathrm{~m}^{-2} \delta^{-1}$ ) (Anderson et al., 2005) provide information with which to evaluate the potential magnitude of cooling associated with shortwave scattering and absorption by aerosols from continental sources at Bermuda based on a simplistic evaluation of the change in $\mathrm{AOD}_{550}$ (Table 6). Radiative efficiencies corresponding to the differences between the median AODs for the NEUS (median of 0.22) and AFR (median of 0.20 ) versus the oceanic regime (median of 0.16) suggests that transport from the NEUS is associated with a top of the atmosphere (TOA) direct radiative forcing on the order of $-1.6 \mathrm{~W} \mathrm{~m}^{-2}$ (radiative cooling), and transport from AFR is associated with a TOA radiative cooling of $-2.5 \mathrm{~W} \mathrm{~m}^{-2}$, relative to the oceanic background. Cooling associated with extreme events may be much greater. For example, based on the this approach, AOD $_{550}$ associated with the dust event of summer 2006 discussed above (0.62) would correspond to a TOA radiative forcing of -16 to $-25 \mathrm{~W} \mathrm{~m}^{-2}$ relative to the oceanic background. Similarly, AOD $_{550}$ associated with the anthropogenic pollution and biomass burning event in June of 2007 (0.37) would correspond to a TOA radiative forcing of -6 to $-13 \mathrm{~W} \mathrm{~m}^{-2}$. We appreciate that this approach does not consider potential complicating influences associated with variability in the oceanic background as a function of transport regime. In this regard, wind velocity (and the associated production of marine aerosol, which scatters incident solar radiation) did not vary significantly among flow regimes during either season (Table 2). Furthermore, we do not have estimates of the relative cloud cover associated with these different flow patterns, which will significantly impact the areal influence of these radiative effects. Despite such limitations, these results do provide useful perspective for the relative impacts of aerosols from different continental sources on direct radiative forcing over the western North Atlantic Ocean.

As a comparison for these estimates, Leibensperger et al. (2012) used historical emission inventories and the GEOS-Chem model to simulate monthly mean aerosol distributions for North America. These were used with the GISS GCM to calculate the direct radiative forcing over the eastern US (east of $100 \mathrm{~W}$ ). They report a cooling $-2.0 \mathrm{~W} \mathrm{~m}^{-2}$ in the period from $1970-1990$, decreasing to $-1.2 \mathrm{~W} \mathrm{~m}^{-2}$ from 1990-2010 as a result of emission controls and declining $\mathrm{SO}_{2}$ concentrations. Globally, direct radiative forcing by aerosols account for mean net cooling of $-0.5 \pm 0.4 \mathrm{~W} \mathrm{~m}^{-2}$ (Forster et al, 2007); Leibensperger et al (2012) estimate that US sources contributed about $-0.03 \mathrm{~W} \mathrm{~m}^{-2}$ ( or $\sim 6 \%$ ) to the global direct radiative forcing by aerosols in 2010 .

\section{Conclusions}

Concentrations, chemical compositions, and corresponding radiative properties of dichotomous aerosols varied significantly as a function of air mass origin. Greatest differences were typically observed during the warm season between continental outflow from the NEUS versus transAtlantic transport from northern Africa and the eastern tropical North Atlantic. Relative to this AFR flow, the NEUS flow was associated with significantly higher concentrations (factors of 2 to 3 based on median values) of bulk particulate nss $\mathrm{SO}_{4}^{2-}, \mathrm{NO}_{3}^{-}$, and $\mathrm{NH}_{4}^{+}$. The difference in bulk nss $\mathrm{SO}_{4}^{2-}$ was driven primarily by higher concentrations associated with the sub- $\mu \mathrm{m}$ size fraction in transport off North America. Based on mean values of $\mathrm{CH}_{3} \mathrm{SO}_{3}^{-}$, anthropogenic sources accounted for $75 \%$ of particulate nss $\mathrm{SO}_{4}^{2-}$ in NEUS flow versus $25 \%$ in AFR flow. Aerosols associated with NEUS flow also exhibited relatively greater scattering and absorption, which was driven primarily by the sub- $\mu \mathrm{m}$ size fraction. Absorption by super- $\mu \mathrm{m}$ aerosol associated with the NEUS and AFR regimes did not differ significantly although the super- $\mu$ m size fraction in AFR flow accounted for a greater fraction of total absorption. These differences 
in optical properties were driven by the nature of the aerosol populations. The significantly greater AAEs for AFR flow reflects the wavelength dependence of absorption by associated large mineral aerosols, whereas the lower AAEs for NEUS flow are consistent with the dominance of smaller combustion-derived aerosols. Despite these differences in near-surface aerosol characteristics at Bermuda, downward column measurements of $\mathrm{AOD}_{550}$ from MODIS and upward column measurements of AOT $_{500}$ by AERONET revealed no significant differences between these two flow regimes. The relatively greater contribution of super- $\mu \mathrm{m}$ aerosol to total extinction in the AFR regime is evident in a weakly significant $(p=0.10)$ difference in the regional EAE estimated from MODIS for NEUS (0.86) versus AFR (0.72). Relative to the median $\mathrm{AOD}_{550}$ for the oceanic regime (representative of a regional background), the higher AODs associated with aerosols transported by NEUS and AFR flow regimes relative to the oceanic background account for a TOA direct radiative forcing on the order of -1.6 to -2.5 , respectively. This suggests interannual differences in the occurrence of major dust events will contribute to variable cooling. However, given the overall predominance of transport from North America on an annual basis, it is reasonable to assume that the radiative influence of these aerosols accounts for a large fraction of atmospheric cooling over the western North Atlantic Ocean. Based on the lower contribution of anthropogenic nss $\mathrm{SO}_{4}^{-}$observed in Bermuda aerosols relative to the early 1990s, these data provide supporting observational evidence that aerosol cooling has declined in recent decades. Stated another way, observed changes in aerosol emissions from North America appear to contribute to warming over the North Atlantic Ocean.

Acknowledgements. We thank Kim Zeeh and Chris Marsay for assisting in field operations and dataprocessing. Peter Sedwick and Andrew Peters supervised operations at the observatory and the Bermuda Institute for Ocean Sciences provided outstanding logistical support. Funding was provided by the National Science Foundation through awards to the University of Virginia (AGS 0541570) and the University of Miami (AGS 0541566). Additional support was provided by NASA through the AERONET and MPLNET programs.

Edited by: P. Quinn

\section{References}

Albrecht, B. A.: Aerosols, cloud microphysics, and fractional cloudiness, Science, 245, 1227-1230, 1989.

Anderson, T. L., Charlson, R. J., Bellouin, N., Boucher, O., Chin, M. Christopher, S. A., Haywoo, J., Kaufman, Y. J., Kinne, S. Ogren, J. A., Remer L. A., Takemura, T., Tanre, D., Torres, O., Trepte, C. R., Wielicki, B. A., Winker, D. M., and Yu, H.: An "A-Train" strategy for Quantifying Direct Climate Forcing by
Anthropogenic Aerosols, B. Am. Meteor. Soc., 12, 1795-1809, 2005.

Anderson, T. L. and Ogren, J. A.: Determining aerosol radiative properties using the TSI 3563 integrating nephelometer, Aerosol Sci. Tech., 29, 57-69, 1998.

Andreae, M. O.: Correlation between cloud condensation nuclei concentration and aerosol optical thickness in remote and polluted regions, Atmos. Chem. Phys., 9, 543-556, doi:10.5194/acp-9-543-2009, 2009.

Andreae, M. O., Rosenfeld, D., Artaxo, P., Costa, A. A., Frank, G. P., Longo, K. M., and Silva-Dias, M. A. F.: Smoking rain clouds over the Amazon, Science, 303, 1337-1342, 2004.

Arimoto, R., Duce, R. A., Ray, B. J., Ellis Jr., W. G., Cullen, J. D., and Merrill, J. T.: Trace elements in the atmosphere over the North Atlantic, J. Geophys. Res., 100, 1199-1213, 1995.

Arimoto, R., Ray, B. J., Lewis, N. F., Tomza, U., and Duce, R. A.: Mass-particle size distributions of atmospheric dust and the dry deposition of dust to the remote ocean, J. Geophys. Res., 102, 15867-15874, 1997.

Aryal, R. P., Voss, K. J., Terman, P. A., Keene, W. C., Moody, J. L., Welton, E. J., and Holben, B. N.: Radiative properties of aerosols in near-surface air and the atmospheric column over the western North Atlantic Ocean at Bermuda, Atmos. Chem. Phys. Discuss., submitted, 2013.

Ball, W. P., Dickerson, R. R., Doddridge, B. G., Stehr, J., Miller, T., Savoie, D., and Carsey, T.: Bulk and size segregated aerosol composition observed during INDOEX 1999: Overview of meteorology and continental impacts, J. Geophys. Res., 8001, doi:10.1029/2002JD002467, 2003.

Bates, T. S., Quinn, P. K., Coffman, D. J., Johnson, J. E., Miller, T. L., Covert, D. S., Wiedensohaler, A., Leinerat, S., Nsowaka, A., and Neusüss, C.: Regional physical and chemical properties of the marine boundary layer aerosol across the Atlantic during Aerosols99: An overview, J. Geophys. Res., 106, 20767-20782, doi:10.1029/2000JD900578, 2001.

Bates, T. S., Anderson, T. L., Baynard, T., Bond, T., Boucher, O., Carmichael, G., Clarke, A., Erlick, C., Guo, H., Horowitz, L., Howell, S., Kulkarni, S., Maring, H., McComiskey, A., Middlebrook, A., Noone, K., O’Dowd, C. D., Ogren, J., Penner, J., Quinn, P. K., Ravishankara, A. R., Savoie, D. L., Schwartz, S. E., Shinozuka, Y., Tang, Y., Weber, R. J., and Wu, Y.: Aerosol direct radiative effects over the northwest Atlantic, northwest Pacific, and North Indian Oceans: estimates based on in-situ chemical and optical measurements and chemical transport modeling, Atmos. Chem. Phys., 6, 1657-1732, doi:10.5194/acp-6-1657-2006, 2006.

Bergstrom, R. W., Pilewskie, P., Russell, P. B., Redemann, J., Bond, T. C., Quinn, P. K., and Sierau, B.: Spectral absorption properties of atmospheric aerosols, Atmos. Chem. Phys., 7, 5937-5943, doi:10.5194/acp-7-5937-2007, 2007.

Birch, M. E. and Cary, R. A.: Elemental carbon-based method for monitoring occupational exposures to particulate diesel exhaust, Aerosol Sci. Technol., 25, 221-241, 1996.

Charlson, R. J. and Heintzenberg, J. (Eds.): Aerosol Forcing of Climate. Wiley, Chichester, New York, 416 pp., 1995.

Christopher, S. A. and Zhang, J.: Shortwave aerosol radiative forcing from MODIS and CERES observations over the oceans, Geophys. Res. Lett., 29, 6-1-6-4, doi:10.1029/2002GL014803, 2002. 
Clarke, A. D. and Kapustin, V. N.: Hemispheric aerosol vertical profiles: Anthropogenic impacts on optical depth and cloud nuclei, Science, 329, 1488-1492, doi:10.1126/science.1188838, 2010.

Forster, P., Ramaswamy, V., Artaxo, P., Berntsen, T., Betts, R., Fahey, D. W., Haywood, J., Lean, J., Lowe, D. C., Myhre, G., Nganga, J., Prinn, R., Raga, Schulz, G. M., and Van Dorland, R.: Changes in Atmospheric Constituents and in Radiative Forcing, In: Climate Change 2007: The Physical Science Basis, Contribution of Working Group I to the Fourth Assessment Report of the Intergovernmental Panel on Climate Change, 129-234, edited by: Solomon, S., Qin, D., Manning, M., Chen, Z., Marquis, M., Averyt, K. B., Tignor, M., and Miller, H. L., Cambridge University Press, Cambridge, UK and New York, NY, USA, 2007.

Galloway, J. N., Likens, G. E., Keene, W. C., and Miller, J. M.: The composition of precipitation in remote areas of the world, J. Geophys. Res., 87, 8771-8786, 1982.

Galloway, J. N., W. C. Keene, R. S. Artz, T. M. Church, and A. H. Knap: Processes controlling the concentrations of $\mathrm{SO}_{4}^{=}$, $\mathrm{NO}_{3}^{-}, \mathrm{NH}_{4}^{+}, \mathrm{H}^{+}, \mathrm{HCOO}_{T}$ and $\mathrm{CH}_{3} \mathrm{COO}_{T}$ in precipitation on Bermuda, Tellus, 41B, 427-443,1989.

Galloway, J. N., Savoie, D. L., Keene, W. C., and Prospero, J. M.: The temporal and spatial variability of scavenging ratios for nss sulfate, nitrate, methanesulfonate and sodium in the atmosphere over the North Atlantic Ocean, Atmos. Environ., 27A, 235-250, 1993.

Heintzenberg, J., Raes, R., Schwartz, S. E., Ackermann, I., Artaxo, I., Bates, T. S., Benkovitz, C., Bigg, K., Bond, T., Brenguier, J.L., Eisele, F. L., Feichter, J., Flossman, A. I., Fuzzi, S., Graf, H.F., Hales, J. M., Herrmann, H., Hoffmann, T., Huebert, B., Husar, R. B., Jaenicke, R., Kärcher, B., Kaufman, Y., Kent, G. S., Kulmala, M., Leck, C., Liousse, C., Lohmann, L., Marticorena, B., McMurry, P., Noone, K., O’Dowd, C., Penner, J. E., Pszenny, A., Putaud, J.-P., Quinn, P. K., Schurath, U., Seinfeld, J. H., Sievering, H., Snider, J., Sokolik, I., Stratmann, F., van Dingenen, R., Westphal, D., Wexler, A. S., Wiedensohler, W., Winker, D. M., and Wilson, J.: Tropospheric Aerosols, Chapter 4, Atmospheric Chemistry in a Changing World, An Integration and Synthesis of a Decade of Tropospheric Chemistry Research, edited by: Brasseur, G. P., Prinn, R. G., and Pszenny, A. A. P., 125-156, Springer-Verlag, Berlin, 2003.

Hegg, D. A., Ferek, R. J., and Hobbs, P. V.: Reply to "Comment on 'Light scattering and cloud condensation nucleus activity of sulfate aerosol measured over the Northeast Atlantic Ocean' by D. A. Hegg et al.”, J. Geophys. Res., 99, 25951-25954, 1994.

Holben, B. N., Tanre, D., Smirnov, A., Eck, T. F., Slutsker, I., Abuhassan, N., Newcomb, W. W., Schafer, J., Chatenet, B., Lavenue, F., Kaufman, Y. J., Vande Castle, J., Setzer, A., Markham, B., Clark, D., Frouin, R., Halthore, R., Karnieli, A., O’Neill, N. T., Pietras, C., Pinker, R. T., Voss, K., and Zibordi, G.: An emerging ground-based aerosol climatology: Aerosol Optical Depth from AERONET, J. Geophys. Res., 106, 12067-12097, 2001.

Huebert, B. J., Zhuang, L., Howell, S., Noone, K., and Noone, B.: Sulfate, nitrate, methanesulfonate, chloride, ammonium, and sodium measurements from ship, island, and aircraft during the Atlantic Stratocumulus Transition Experiment/Marine Aerosol Gas Exchange, J. Geophys. Res., 101, 4413-4423, 1996.

IPCC 2007, Climate Change 2007: The Physical Science Basis, Contribution of Working Group I to the Fourth Assessment Report of the Intergovernmental Panel on Climate Change,
Solomon, S., Qin, D., Manning, M., Chen, Z., Marquis, M., Averyt, K. B., Tignor, M., and Miller, H. L., (eds.), Cambridge University Press, Cambridge, United Kingdom and New York, NY, USA, 996 pp., 2007.

Kaufman, Y. J., Tanre, D., Holben, B. N., Mattoo, S., Remer, L. A., Eck, T. F., Vaughan, J., and Chatenet, B.: Aerosol radiative impact on spectral solar flux at the surface, derived from principalplane sky measurements, J. Atmos. Sci., 59, 635-646, 2002.

Keene, W. C., Pszenny, A. A. P., Galloway, J. N., and Hawley, M. E.: Sea-salt corrections and interpretation of constituent ratios in marine precipitation, J. Geophys. Res., 91, 6647-6658, 1986.

Keene, W. C., Talbot, R. W., Andreae, M. O., Beecher, K., Berresheim, H., Castro, M., Farmer, J. C., Galloway, J. N., Hoffman, M. R., Li, S.-M., Maben, J. R., Munger, J. W., Norton, R. B., Pszenny, A. A. P., Puxbaum, H., Westberg, H., and Winiwarter, W.: An intercomparison of measurement systems for vapor- and particulate-phase concentrations of formic and acetic acids, J. Geophys. Res., 94, 6457-6471, 1989.

Keene, W. C., Pszenny, A. A. P., Maben, J. R., Stevenson, E., and Wall, A.: Closure evaluation of size-resolved aerosol $\mathrm{pH}$ in the New England coastal atmosphere during summer, J. Geophys. Res., 109, D23307, doi:10.1029/2004JD004801, 2004.

Keene, W. C., Long, M. S., Pszenny, A. A. P., Sander, R., Maben, J. R., Wall, A. J., O’Halloran, T. L., Kerkweg, A., Fischer, E. V., and Schrems, O.: Latitudinal variation in the multiphase chemical processing of inorganic halogens and related species over the eastern North and South Atlantic Oceans, Atmos. Chem. Phys., 9, 7361-7385, doi:10.5194/acp-9-7361-2009, 2009.

Keene, W. C., Moody, J. L., Galloway, J. N., Propsero, J. M., Cooper, O. R., Eckhardt, S., and Maben, J. R.: Long-term trends in aerosol and precipitation composition over the western North Atlantic Ocean at Bermuda, Atmos. Chem. Phys. Discuss., in preparation, 2014.

Koch, D., Bond, T. C., Streets, D., Unger, N., and van der Werf, R. G.: Global impacts of aerosols from particular source regions and sectors, J. Geophys. Res., 112, D02205, doi:10.1029/2005JD007024, 2007.

Koren, I., Kaufman, Y. J., Remer, L. A., and Martins, J. V.: Measurements of the effect of Amazon smoke on inhibition of cloud formation, Science, 303, 1342-1345, 2004.

Lack, D. A., Cappa, C. D., Covert, D. S., Baynard, T., Massoli, P., Sierau, B., Bates, T. S., Quinn, P. K., Lovejoy, E. R., and Ravishankara, A. R.: Bias in filter-based aerosol light absorption measurements due to organic aerosol loading: Evidence from ambient measurements, Aerosol Sci. Technol., 42, 1033-1041, 2008.

Lack, D. A., Quinn, P. K., Massoli, P., Bates, T. S., Coffman, D., Covert, D. S., Sierau, B., Tucker, S., Baynard, T., Lovejoy, E., Murphy, D. M., and Ravishankara, A. R.: Relative humidity dependence of light absorption by mineral dust after long-range atmospheric transport from the Sahara, Geophys. Res. Lett., 36, L24805, doi:10.1029/2009GL041002, 2009.

Leibensperger, E. M., Mickley, L. J., Jacob, D. J., Chen, W.-T., Seinfeld, J. H., Nenes, A., Adams, P. J., Streets, D. G., Kumar, N., and Rind, D.: Climatic effects of 1950-2050 changes in US anthropogenic aerosols - Part 1: Aerosol trends and radiative forcing, Atmos. Chem. Phys., 12, 3333-3348, doi:10.5194/acp-12-33332012, 2012. 
Li, X., Maring, H., Savoie, D., Voss, K., and Prospero, J. M.: Dominance of mineral dust in aerosol light-scattering in the North Atlantic trade winds, Nature, 380, 416-419, 1996.

Liu, B. Y. H., Pui, D. Y. H., Wang, X. Q., and Lewis, C. W.: Sampling of carbon fiber aerosols, Aerosol Sci. Technol., 2, 499-511, 1983.

Maring, H., Savoie, D. L., Izaguirre, M. A., McCormick, C., Arimoto, R., Prospero, J. M., and Pilinis, C.: Aerosol physical and optical properties and their relationship to aerosol composition in the free troposphere at Izana, Tenerife, Canary Islands during July 1995, J. Geophys. Res., 97, 11575-11589, 2000.

Marple, V. A., Rubow, K. L., and Behm, S. M.: A microorifice uniform deposit impactor (MOUDI): Description, calibration, and use, Aerosol Sci. Technol., 14, 434-446, 1991.

Molina, L. T., Madronich, S., Gaffney, J. S., Apel, E., de Foy, B., Fast, J., Ferrare, R., Herndon, S., Jimenez, J. L., Lamb, B., Osornio-Vargas, A. R., Russell, P., Schauer, J. J., Stevens, P. S., Volkamer, R., and Zavala, M.: An overview of the MILAGRO 2006 Campaign: Mexico City emissions and their transport and transformation, Atmos. Chem. Phys., 10, 8697-8760, doi:10.5194/acp-10-8697-2010, 2010.

Moody, J. L. and. Gallowa, J. Ny: Quantifying the relationship between atmospheric transport and the chemical composition of precipitation on Bermuda, Tellus, 40B, 463-479, 1988.

Moody, J. L., Oltmans, S. J., Levy, H., and Merrill, J. T.: Transport climatology of tropospheric ozone: Bermuda, 1988-1991, J. Geophys. Res., 100, 7179-7194, 1995.

Moody, J. L., Keene, W. C., Cooper, O. R., Voss, K. J., Aryal, R., Eckhardt, S., Holben, B., Maben, J. R., Izaguirre, M. A., and Galloway, J. N.: Flow climatology for physicochemical properties of dichotomous aerosol over the western North Atlantic Ocean at Bermuda, Atmos. Chem. Phys. Discuss., 13, 22383-22444, doi:10.5194/acpd-13-22383-2013, 2013.

Murphy, D. M., Chow, J. C., Leibensperger, E. M., Malm, W. C., Pitchford, M., Schichtel, B. A., Watson, J. G., and White, W. H.: Decreases in elemental carbon and fine particle mass in the United States, Atmos. Chem. Phys., 11, 4679-4686, doi:10.5194/acp-11-4679-2011, 2011.

Novakov, T., Bates, T. S., and Quinn, P. K.: Shipboard measurements of concentrations and properties of carbonaceous aerosols during ACE-2, Tellus, 52B, 228-238, 2000.

O’Dowd, C. D., Facchini, M. C., Cavalli, F., Cebrunis, D., Mircea, M., Decesari, S., Fuzzi, S., Yoon, Y. J., and Putard, J.-P.: Biogenically driven organic contribution to marine aerosol, Nature, 431, 676-680, 2004.

Prospero, J. M. and Savoie, D. L.: Effect of continental sources on nitrate concentrations over the Pacific Ocean, Nature, 339, 687689, 1989.

Quinn, P. K. and Bates, T. S.: Regional aerosol properties: Comparison of boundary layer measurements from ACE1, ACE2, Aerosols99, INDOEX, ACE Asia, TARFOX, and NEAQS, J. Geophys. Res., 110, D14202, doi:10.1029/2004JD004755, 2005.

Ramanathan, V., Crutzen, P. J., Kiehl, J. T., and Rosenfeld, D.: Aerosols, climate, and the hydrologic cycle, Science, 294, 21192124, 2001

Reid, J. S., Hobbs, P. V., Liousse, C., Martins, J. V., Weiss, R. E., and Eck, T. F.: Comparisons of techniques for measuring shortwave absorption and black carbon content of aerosols from biomass burning in Brazil, J. Geophys. Res., 103, 32031-32040, 1998.
Reid, E. A., Reid, J. S., Meier, M. M., Dunlap, M. R., Cliff, S. S., Broumas, A., Perry, K., and Maring, H.: Characterization of African dust transported to Puerto Rico by individual particle and size segregated bulk analysis, J. Geophys. Res., 108, 8591, doi:10.1029/2002JD002935, 2003.

Russell, P. B., Hobbs, P. V., and Stowe L. L.: Aerosol properties and radiative effects in the United States East Coast haze plume: An overview of the Tropospheric Aerosol Radiative Forcing Observational Experiment (TARFOX), J. Geophys. Res., 104, 2213 2222, 1999.

Savoie, D. L., Prospero, J. M., Oltmans, S. J., Graustein, W. C., Turekian, K. K., Merrill, J. T., and Levy II, H.: Sources of nitrate and ozone in the marine boundary layer of the tropical North Atlantic, J. Geophys. Res., 97, 11575-11589, 1992.

Savoie, D. L., Arimoto, R., Keene, W. C., Prospero, J. M., Duce, R. A., and Galloway, J. N.: Marine biogenic and anthropogenic contributions to non-sea-salt sulfate in the marine boundary layer over the North Atlantic Ocean, J. Geophys. Res., 107, 4356, doi:10.1029/2001JD000970, 2002.

Seibert, P. and Frank, A.: Source-receptor matrix calculation with a Lagrangian particle dispersion model in backward mode, Atmos. Chem. Phys., 4, 51-63, doi:10.5194/acp-4-51-2004, 2004.

Sierau, B., Covert, D. S., Coffman, D. J., Quinn, P. K., and Bates, T. S.: Aerosol optical properties during the 2004 New England Air Quality Study-Intercontinental Transport and Chemical Transformation: Gulf of Maine surface measurements Regional and case studies, J. Geophys. Res., 111, D23S37, doi:10.1029/2006JD007568, 2006.

Smirnov, A., Holben, B., Sakerin, S. M., Kabanov, D. M., Slutcker, I., Chin, M., Diehl, T. L., Remer, L. A., Kahn, R., Ignatov, A., Liu, L., Mishchernko, M., Eck, T. F., Kuscera, T. L., Giles, D., and Kopelevich, O. V.:Ship-based aerosol optical depth measurements in the Atlantic Ocean: Comparison with satellite retrievals and GOCART model, Geophys. Res. Lett., 33, L14817, doi:10.1029/2006GL026051, 2006.

Stohl, A., Hittenberger, M., and Wotawa, G.: Validation of the Lagrangian particle dispersion model FLEXPART against large scale tracer experiment data, Atmos. Environ., 32, 4245-4264, 1998.

Stohl, A., C. Forster, S. Eckhardt, N. Spichtinger, H. Huntrieser, J. Heland, H. Schlager, S. Wilhelm, F. Arnold, and O. Cooper: A backward modeling study of intercontinental pollution transport using aircraft measurements, J. Geophys. Res., 108, 4370, doi:10.1029/2002JD002862, 2003.

Stohl, A., Forster, C., Frank, A., Seibert, P., and Wotawa, G.: Technical note: The Lagrangian particle dispersion model FLEXPART version 6.2, Atmos. Chem. Phys., 5, 2461-2474, doi:10.5194/acp-5-2461-2005, 2005.

Trapp, J. M., Millero F. J.,, and Prospero, J. M.: Temporal variability of the elemental composition of African dust measured in trade wind aerosols at Barbados and Miami, Mar. Chem., 120, 71-82, 2010a.

Trapp, J. M., Millero, F. J., and Prospero, J. M.: Trends in the solubility of iron in dust-dominated aerosols in the equatorial Atlantic trade winds: Importance of iron speciation and sources, Geochem, Geophys. Geosyst., 11, Q03014, doi:10.1029/2009GC002651, 2010b.

Turekian, V. C., Macko, S. A., and Keene, W. C.: Application of stable sulfur isotopes to differentiate sources of size-resolved par- 
ticulate sulfate in polluted marine air at Bermuda during spring, Geophys. Res. Lett., 28, 1491-1494, 2001.

Turekian, V. C., Macko, S. A., and Keene, W. C.: Concentrations, isotopic compositions, and sources of size-resolved, particulate organic carbon and oxalate in near-surface marine air at Bermuda during spring, J. Geophys. Res., 108, 4157, doi:10.1029/2002JD002053, 2003.

Wang, W., Rood, M. J., Carrico, C. M., Covert, D. S., Quinn, P. K., and Bates, T. S.: Aerosol optical properties along the northeast coast of North America during the New England Air Quality Study-Intercontinental Transport and Chemical Transformation 2004 campaign and the influence of aerosol composition, J. Geophys. Res., 112, D10S23, doi:10.1029/2006JD007579, 2007.

Welton, E. J., Voss, K. J., Gordon, H. R., Maring, H., Smirnov, A., Holben, B., Schmid, B., Livingston, J. M., Russell, B. P., Durkee, P. A., Formenti, P., and Andreae, M. O.: Ground-based lidar measurements of aerosols during ACE-2: Instrument description, results, and comparisons with other ground-based and airborne measurements, Tellus, 52B, 636-651, 1999.
Wilson, T. R. S.: Salinity and the major elements of sea water, in Chemical Oceanography, edited by: Riley, J. P. and Skirrow, G., Vol. 1, 2nd Edition, 365-413, Academic Press, Orlando, FL, 1975.

Yu, H., Kickinson, R. E., Chin, M., Kaufman, Y. J., Zhou, M., Zhou, L., Tian, Y., Dubovik, O., and HOlben, B. N.: The direct radiative effect of aerosols as determined from a combination of MODIS and GOCART simulations, J. Geophys. Res., 109, D03206, doi:10.1029/2003JD003914, 2004.

Yu, H., Remer, L. A., Chin, M., Bian, H., Tan, Q., Yuan, T., and Zhang, Y.: Aerosols from Overseas Rival Domestic Emissions over North America, Science, 337, 556-569, 2012. 